\title{
The influence of sea- and land-breeze circulations on the diurnal variability in precipitation over a tropical island
}

\author{
Lei Zhu ${ }^{1,2,3}$, Zhiyong Meng ${ }^{1}$, Fuqing Zhang ${ }^{2,3}$, and Paul M. Markowski ${ }^{2}$ \\ ${ }^{1}$ Laboratory for Climate and Ocean-Atmosphere Studies, Department of Atmospheric and Oceanic Sciences, \\ School of Physics, Peking University, Beijing, China \\ ${ }^{2}$ Department of Meteorology and Atmospheric Science, The Pennsylvania State University, University Park, \\ Pennsylvania, USA \\ ${ }^{3}$ Center for Advanced Data Assimilation and Predictability Techniques, The Pennsylvania State University, \\ University Park, Pennsylvania, USA
}

Correspondence to: Zhiyong Meng (zymeng@pku.edu.cn)

Received: 9 April 2017 - Discussion started: 24 April 2017

Revised: 21 August 2017 - Accepted: 17 September 2017 - Published: 8 November 2017

\begin{abstract}
This study examines the diurnal variation in precipitation over Hainan Island in the South China Sea using gauge observations from 1951 to 2012 and Climate Prediction Center MORPHing technique (CMORPH) satellite estimates from 2006 to 2015, as well as numerical simulations. The simulations are the first to use climatological mean initial and lateral boundary conditions to study the dynamic and thermodynamic processes (and the impacts of land-sea breeze circulations) that control the rainfall distribution and climatology. Precipitation is most significant from April to October and exhibits a strong diurnal cycle resulting from land-sea breeze circulations. More than $60 \%$ of the total annual precipitation over the island is attributable to the diurnal cycle with a significant monthly variability. The CMORPH and gauge datasets agree well, except that the CMORPH data underestimate precipitation and have a $1 \mathrm{~h}$ peak delay. The diurnal cycle of the rainfall and the related landsea breeze circulations during May and June were well captured by convection-permitting numerical simulations with the Weather Research and Forecasting (WRF) model, which were initiated from a 10-year average ERA-Interim reanalysis. The simulations have a slight overestimation of rainfall amounts and a $1 \mathrm{~h}$ delay in peak rainfall time. The diurnal cycle of precipitation is driven by the occurrence of moist convection around noontime owing to low-level convergence associated with the sea-breeze circulations. The precipitation intensifies rapidly thereafter and peaks in the afternoon with the collisions of sea-breeze fronts from different sides of the
\end{abstract}

island. Cold pools of the convective storms contribute to the inland propagation of the sea breeze. Generally, precipitation dissipates quickly in the evening due to the cooling and stabilization of the lower troposphere and decrease of boundary layer moisture. Interestingly, the rather high island orography is not a dominant factor in the diurnal variation in precipitation over the island.

\section{Introduction}

On tropical islands, the diurnal precipitation cycle tends to be driven by the land-sea breeze (LSB), as well as mountainvalley wind systems (Mapes et al., 2003; Qian, 2008; Crosman and Horel, 2010). Both rain gauge and satellite observations indicate that rainfall peaks in the late afternoon over inland regions, and in the early morning or evening offshore (Yang and Slingo, 2001).

The emergence of high temporal and spatial resolution satellite-estimated precipitation observations, such as those provided by Tropical Rainfall Measuring Mission (TRMM, Huffman et al., 2007) and Climate Prediction Center MORPHing technique (CMORPH, Joyce et al., 2004), has greatly improved our understanding of tropical precipitation. Precipitation amounts are much higher over tropical islands than their surrounding oceans (Qian, 2008). More than $34 \%$ of the total precipitation in the tropics is attributable to precipitation over land (Ogrino et al., 2016). Moreover, tropical pre- 
cipitation is usually due to convection (Dai, 2001). Tropical convection is also well known to have an important influence on the large-scale atmospheric circulation (Neale and Slingo, 2003; Sobel et al., 2011).

Many efforts have been made to understand the mechanisms behind the diurnal precipitation cycle over tropical islands. With CMORPH data and regional climate model simulations, Qian (2008) found that sea-breeze convergence, mountain-valley winds and cumulus merger process are the predominant reasons for the diurnal precipitation cycles, while the underrepresentation of islands and terrain results in an underestimation of precipitation. Hassim et al. (2016) examined the diurnal cycle of rainfall over New Guinea with a $4 \mathrm{~km}$ convection-permitting WRF model. They found the importance of sea breeze in the initiation of rainfall but focused on large-scale atmospheric properties preferred by the propagation of systems offshore at night. They also found that orography and the coastline along with gravity waves were beneficial for the longevity and maintenance of the convection systems, though they are not the fundamental reasons for the convection initiation.

The diurnal cycle of tropical rainfall is usually poorly captured by most global climate models (GCMs) and even cloud-resolving models (CRMs), owing to model uncertainties in depicting the physical mechanisms that underlie the diurnal precipitation cycle (Yang and Slingo, 2001; Qian, 2008; Nguyen et al., 2015). Yang and Slingo (2001) found that the deficiency of model's physical parameterizations may be the main reason for the difficulty in capturing the observed phase of diurnal cycle in convection. Diurnal variability is only captured in some places or months where the signals are strong, while at other times, the diurnal signals are captured but with a large timing error of the maxima and minima. Studies show that the LSB may have different contributions to the diurnal variabilities of precipitation at different places (Keenan et al., 1988; Qian, 2008; Wapler and Lane, 2012; Chen et al., 2017). Precipitation tends to be initiated by the convergence of land breezes (Wapler and Lane, 2012) and sea breezes (Qian, 2008) over gulf and island areas respectively. Interactions between land breeze and prevailing wind are likely to produce precipitation over the coastal area or tropical islands (Keenan et al., 1988; Chen et al., 2017). Recent studies (Bao et al., 2013; Chen et al., 2016, 2017) have also found that convectively driven cold pools and latent cooling, as well as environmental wind and moisture, may play important roles in the propagation and maintenance of diurnal rainfall in coastal regions. How cold pools and latent cooling affect the diurnal cycle of rainfall and related LSB over a tropical island has not been studied extensively.

This work aims to examine the diurnal cycle of precipitation and the related LSB over Hainan Island in the South China Sea. Hainan Island is a tropical island located off the southern coast of China (Fig. 1). It is one of the rainiest areas in China and is influenced by a variety of synoptic-scale and mesoscale weather systems, such as monsoon, tropical

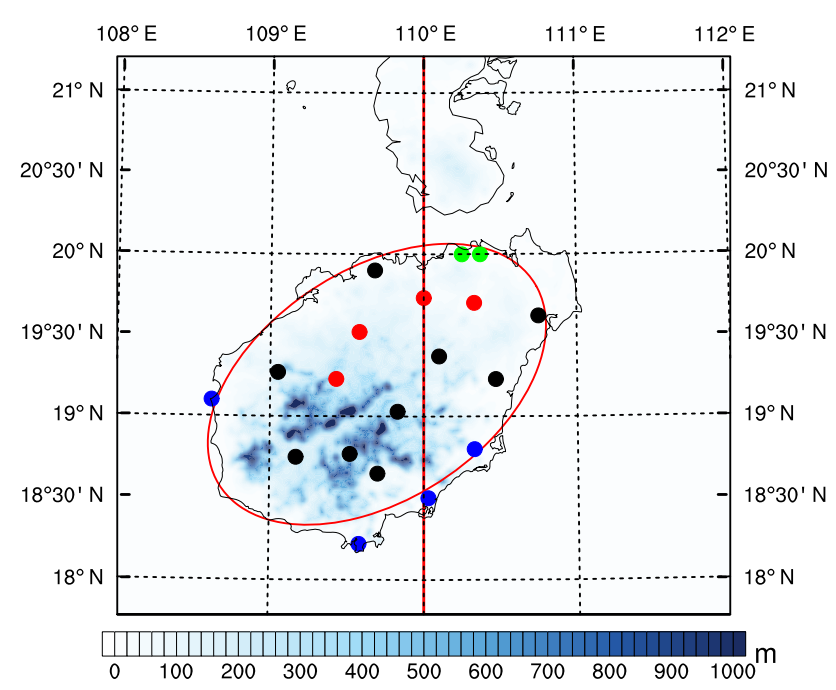

Figure 1. Configuration of model domain, gauge-based station points (colored dots correspond to the time series shown in Fig. 2) over Hainan Island and the terrain height (shading, $\mathrm{m}$ ). The red ellipse is the idealized representation of the island (used for the idealized simulations), and the red vertical line indicates the location of the vertical cross sections shown in Figs. 14 and 16.

cyclones, LSB, and mountain-plain solenoids. The island's topography features mountains in the southwest, with a peak altitude of approximately $1000 \mathrm{~m}$ above the sea level (shaded in Fig. 1) and plains in the northeast.

The characteristics of precipitation and LSB over Hainan Island have been examined via statistical methods based on either surface observation or modeling simulations (Tu et al., 1993; Zhai et al., 1998; Zhang et al., 2014; Liang and Wang, 2017). Based on nine station-based wind observations, Zhang et al. (2014) found that LSB occurs more frequently in summer and autumn, though their findings are limited in using observations in only 1 month of one season. Most recently, Liang and Wang (2017) examined the relationship between the sea breeze and precipitation of Hainan Island using surface wind and precipitation observations along with the global reanalysis over several years. They hypothesized that the seasonal precipitation is due to the initiation of convection by the LSB, but they did not provide thorough investigation on how the LSB circulations trigger and enhance the precipitation over Hainan Island.

The objective of this study is to investigate the diurnal precipitation variation over Hainan Island and the detailed physical mechanisms related to LSB forcing and variability. This is the first time that semi-idealized convection-permitting simulations have been used with climatological mean initial conditions and lateral boundary conditions to study the dynamic and thermodynamic processes (and the impacts of LSB circulations) that control the rainfall distribution and climatology over a tropical island. We also highlight the removal of the terrain effect along with a further simplifica- 
tion using a perfect oval-shaped island. The study relies on rain gauge observations and satellite-derived precipitation estimates, as well as convection-permitting numerical simulations. Section 2 describes the dataset and the methodology. Section 3 documents the diurnal precipitation variation in each month, as well as its fraction of the total precipitation that can be attributed to the diurnal cycle. The relationship between the precipitation and surface winds during the first rainy season (May and June, which is defined relative to the second rainy season, July to September, of southern China when precipitation is mainly caused by typhoons) are also analyzed. The model configuration and results of the simulations are presented in Sect. 4. Conclusions are presented in Sect. 5.

\section{Observation dataset and methodology}

Rainfall was analyzed using 19 rain gauges on Hainan Island (Fig. 1). The gauges are relatively evenly distributed across the island. The sampling frequency is $1 \mathrm{~h}$, which is dense enough to represent the diurnal precipitation variation over the island. The dataset spans 62 years (1951-2012), though full records exist for only a subset of this period at some of the stations, owing to the fact that the stations were built at different times (the detailed dataset periods for each station are shown in Table 1). Surface temperature and wind observations obtained at the same locations over a 4-year period (2007-2010) were used to investigate the land and sea breezes. The surface precipitation observations are augmented by National Oceanic and Atmospheric Administration (NOAA) and CMORPH data derived from low-Earthorbiting and geostationary satellites (Joyce et al., 2004). The CMORPH grid with a temporal resolution of $30 \mathrm{~min}$ is $0.7277^{\circ}$ by $0.7277^{\circ}$ (approximately $8 \mathrm{~km}$ by $8 \mathrm{~km}$ ). Ten years of CMORPH data (2006-2015) were used.

A series of convection-permitting numerical simulations were performed with the Advanced Research Weather Research and Forecasting (ARW, Skamarock et al., 2008) model version 3.7.1 to investigate dynamical features of the diurnal cycle of precipitation and its physical mechanisms in particular with regards to LSB forcing. Initial and lateral boundary conditions were provided by the European Center for Medium-Range Weather forecast Interim (ERA-Interim) reanalysis data (Dee et al., 2011) of $0.75^{\circ} \times 0.75^{\circ}$ grid spacing. Only one domain was used with $225 \times 205$ grid points and a horizontal grid spacing of $2 \mathrm{~km}$. A total of 50 vertical levels were used with the model top at $50 \mathrm{hPa}$. The Yonsei University (YSU) boundary scheme (Hong et al., 2006), the Dudhia shortwave radiation (Dudhia, 1989), the Rapid Radiative Transfer Model longwave radiation scheme (Iacono et al., 2008), the single-moment 5-class microphysics (Hong et al., 2004), five-layer thermal diffusion land surface, and revised MM5 surface layer schemes were used, while no cumulus parameterization was used in this study.
The initial conditions of all simulations were the average of ERA-Interim reanalysis data at 00:00 UTC in May and June of 2006-2015. The lateral boundary conditions were obtained in the same way as the initial conditions, cycled from 00:00 to 06:00, 12:00, and 18:00 UTC. The experiment REAL was initiated with the unmodified initial and lateral boundary conditions to simulate the diurnal characteristics. The experiment NoTER is the same as REAL except that the orography over Hainan Island is removed in the initial conditions in order to isolate the influence of the island's terrain. Simplifying the influences of land category and coastline, the experiment IDEAL was constructed with an idealized elliptical island to replace the real Hainan Island in the initial condition. The idealized island has a similar size and orientation, and is located at the same place as Hainan Island (Fig. 1), covered with uniform grassland (LU_INDEX $=7$ in WRF model), while other areas of the model domain are set as ocean. In order to examine the impact of latent heating/cooling on the LSB and related rainfall, the sensitivity experiment FakeDry was performed similarly to the IDEAL experiment, except that latent heating and cooling in the model was turned off (no_mp_heating = 1 in WRF model). Another sensitivity experiment NOVAP was performed similarly to the IDEAL experiment except that the evaporation of liquid water, which prevents the cold pool generation from moisture convection process, was turned off. A similar methodology has been used to study diurnal cycles of precipitation in many different regions (Trier et al., 2010; Sun and Zhang, 2012; Bao and Zhang, 2013; Chen et al., 2016, 2017). The biggest advantage of this method is that it is able to capture the general characteristics of the diurnal cycle of precipitation and the related dynamical processes instead of just focusing on a single case. All simulations were integrated for 1 month. The mean over the last 26 days was used for the analyses in order to alleviate the spin-up issue and day-to-day variability.

\section{Observation analysis}

\subsection{Diurnal variation in precipitation and its seasonal-dependent features}

Diurnal variations in precipitation were examined at each single station in each month based on the hourly gauge precipitation observation averaged over the period from 1951 to 2012. The hourly precipitation evolution shows a significant seasonal cycle over the island. Most of the precipitation falls from April to October, which is the monsoon season, and exhibits a distinct diurnal cycle during that period, whereas less precipitation and lack of a strong diurnal cycle characterize the other months (Fig. 2). The seasonal variability is related to the annual cycle of the East Asian Monsoon. April and September are the two transitional periods of the low-level 
Table 1. Station observation period used over Hainan Island.

\begin{tabular}{llllll}
\hline Station No. & Latitude & Longitude & Height $(\mathrm{m})$ & Observation period (yyyy mm) & Name \\
\hline 59757 & 20 & 110.37 & 9.9 & $197701-201212$ & Qiongshan \\
59758 & 20 & 110.25 & 63.5 & $195101-201212$ & Haikou \\
59838 & 19.1 & 108.62 & 7.6 & $195506-201212$ & Dongfang \\
59842 & 19.9 & 109.68 & 31 & $196201-201212$ & Lingao \\
59843 & 19.73 & 110 & 31.4 & $195901-201212$ & Dengmai \\
59845 & 19.52 & 109.58 & 169 & $195505-201212$ & Zanzhou \\
59847 & 19.27 & 109.05 & 98.1 & $196605-201212$ & Changjiang \\
59848 & 19.23 & 109.43 & 215.6 & $196201-201212$ & Baisha \\
59849 & 19.03 & 109.83 & 250.9 & $195602-201212$ & Qiongzhong \\
59851 & 19.7 & 110.33 & 24.2 & $196301-201212$ & Dingan \\
59854 & 19.37 & 110.1 & 118.3 & $196301-201212$ & Tunchang \\
59855 & 19.23 & 110.47 & 24 & $195509-201212$ & Qionghai \\
59856 & 19.62 & 110.75 & 21.7 & $195901-201212$ & Ledong \\
59940 & 18.75 & 109.17 & 155 & $196202-201212$ & Wuzhishan \\
59941 & 18.77 & 109.52 & 328.5 & $196301-201212$ & Baoting \\
59945 & 18.65 & 109.7 & 68.6 & $196509-201212$ & Sanya \\
59948 & 18.22 & 109.58 & 419.4 & $196201-201212$ & Wanning \\
59951 & 18.8 & 110.33 & 39.9 & $196201-201212$ & Lingshui \\
59954 & 18.5 & 110.03 & 13.9 & $195601-201212$ & \\
\hline
\end{tabular}

prevailing wind; the prevailing wind strongly influences the transport of water vapor and precipitation.

The diurnal precipitation cycle has the maximum precipitation at 15:00 local standard time (LST, UTC +8) in most months during the warm season, except at 16:00 LST in April and July. No second precipitation peak was observed, which is different from studies of other tropical islands in which a second peak between midnight and early morning has been noted (Kishtawal and Krishnamurti, 2001; Wapler and Lane, 2012). The second nocturnal peak was found to be closely related to convection caused by the mountain-plains solenoid that propagates offshore and coincides with the land breeze during the night or early morning.

The diurnal precipitation cycle shows location-dependent features (Fig. 2). We grouped the stations with different colors based on their similarity in diurnal variations, which to a large extent are correlated with their geographical locations. No heavy rainfall or distinct variability was observed at stations along the southern coastline (blue dots in Fig. 1 and blue lines in Fig. 2). All the rest of the island stations share similar diurnal peak precipitation times with the red-dot stations (in red lines), having the highest peak values from April to July, while in August and September both the red-dot and black-dot stations (mostly inland) share the strongest peaks.

Even though the distribution of gauge-based precipitation stations is relatively even across the island, the observations are still too sparse to analyze the detailed rainfall pattern over the island. For this reason, satellite-derived precipitation CMORPH data were also used to examine the diurnal rainfall variation for each of the 19 gauge stations. The hourly diurnal precipitation variation derived from the $\mathrm{CMORPH}$ data agree well with the rain gauge observations in each month (Fig. 3), though the CMORPH amounts are slightly smaller. The time of peak precipitation in the warm season (from May to $\mathrm{Au}-$ gust) is delayed by $1 \mathrm{~h}$ in most months in the CMORPH data (maximum at 16:00 LST) relative to the peak in the gaugebased observations. These results indicate good agreement between the CMORPH data and gauges, in particular for the warm-season months that are the focus of this study.

The fraction of the diurnal precipitation in the total precipitation over the island in each month was examined with the CMORPH data (Fig. 4). Similarly to He and Zhang (2010) and Bao et al. (2011), the diurnal precipitation fraction was defined as the mean rainfall rate at each $1 \mathrm{~h}$ inter$\mathrm{val}=\frac{\sum_{t=0}^{23}\left|\left(r_{t}-\bar{r}\right)\right|}{r_{d}}$, in which $r_{t}$ is the mean hourly precipitation at each hour $t(0-23), \bar{r}$ is the mean hourly precipitation at all hours, and the $r_{d}$ is the daily mean precipitation. The diurnal precipitation accounts for a large fraction of the total precipitation over the island in most months (Fig. 4). In particular, the total precipitation in May is almost entirely attributable to the diurnal cycle (Fig. 4e). The diurnal contribution of the total precipitation exceeds $60 \%$ averaged for the whole year and over the whole island, although the magnitude is smaller in September and October. The diurnal precipitation fraction value exceeds $20 \%$ in August and September (Fig. 4h and i). Moreover, the area exhibiting a large magnitude of diurnal precipitation roughly coincides with the region also having the most accumulated precipitation. However, the diurnal precipitation fraction is not quite related to the precipitation intensity. The precipitation is extremely light in March and somewhat heavy in September. However, the diurnal precipitation fractions are reversed (smaller 


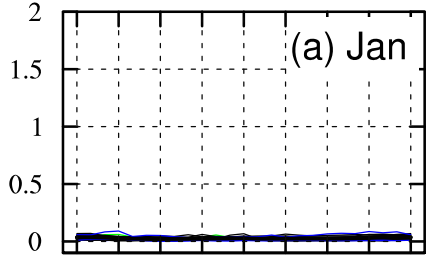

$\begin{array}{lllllllll}06 & 09 & 12 & 15 & 18 & 21 & 00 & 03 & 06\end{array}$

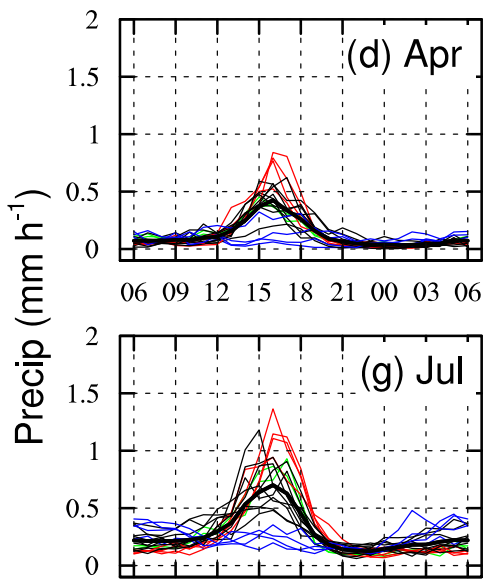

$\begin{array}{lllllllll}06 & 09 & 12 & 15 & 18 & 21 & 00 & 03 & 06\end{array}$

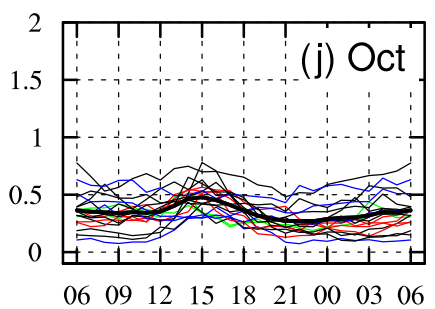

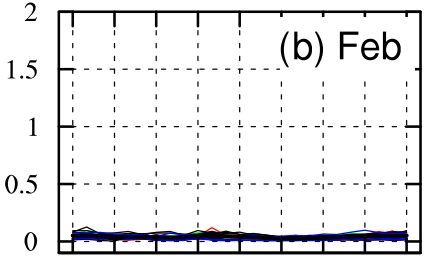

$\begin{array}{lllllllll}06 & 09 & 12 & 15 & 18 & 21 & 00 & 03 & 06\end{array}$

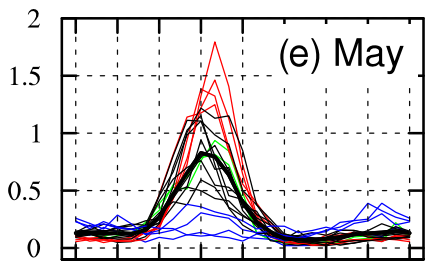

$\begin{array}{llllllllll}06 & 09 & 12 & 15 & 18 & 21 & 00 & 03 & 06\end{array}$

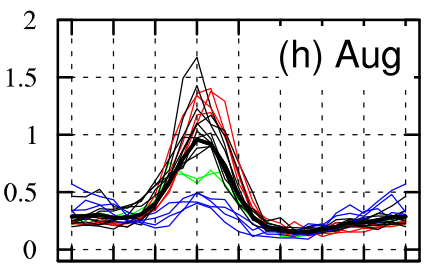

$\begin{array}{lllllllll}06 & 09 & 12 & 15 & 18 & 21 & 00 & 03 & 06\end{array}$

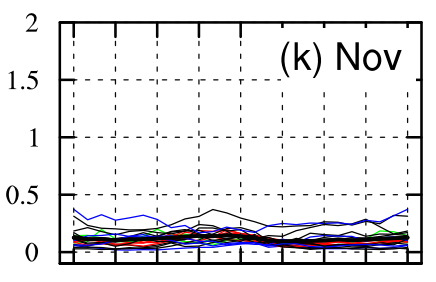

$\begin{array}{lllllllll}06 & 09 & 12 & 15 & 18 & 21 & 00 & 03 & 06\end{array}$

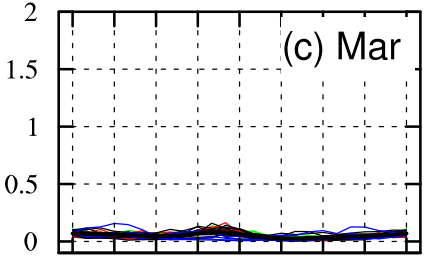

$\begin{array}{llllllllll}06 & 09 & 12 & 15 & 18 & 21 & 00 & 03 & 06\end{array}$

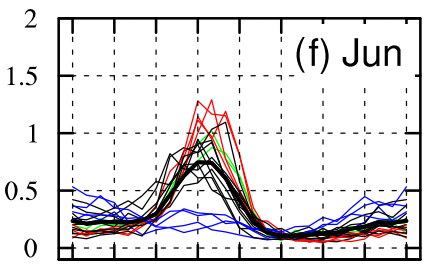

$\begin{array}{llllllllll}06 & 09 & 12 & 15 & 18 & 21 & 00 & 03 & 06\end{array}$

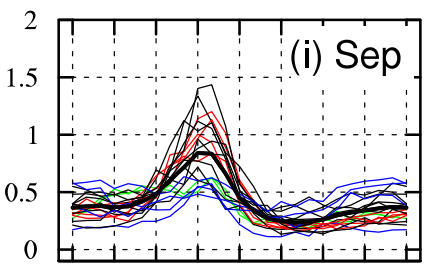

$\begin{array}{lllllllll}06 & 09 & 12 & 15 & 18 & 21 & 00 & 03 & 06\end{array}$

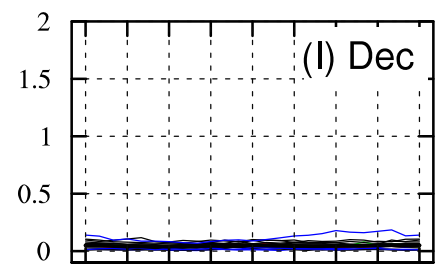

$\begin{array}{lllllllll}06 & 09 & 12 & 15 & 18 & 21 & 00 & 03 & 06\end{array}$

Time (LST)

Figure 2. Average rainfall accumulations by hour for each month of the year, obtained from the rain gauge network. The color is consistent with the colored dots over the island in Fig. 1. LST means local standard time.

fractions in September, greater fractions in March), which is likely related to different physical processes of the precipitation in those months. The detailed physical processes that lead to the steady decrease of diurnal precipitation fraction from May to October before increasing again are beyond the scope of the current study. The possible reasons could be attributed to the synoptic-scale storms, typhoons, prevailing winds, the land-sea temperature contrast, and atmospheric moisture content, which will be explored in our future study.

\subsection{The diurnal cycle of precipitation, land breezes, and sea breezes in May and June}

A more detailed analysis of the diurnal rainfall variation in May and June was carried out because of the intense hourly mean rainfall and high diurnal precipitation fraction. In May, the prevailing warm and wet southwesterly monsoon airflow transports abundant moisture from the ocean to Hainan Is- land. A distinct diurnal cycle of precipitation, with a single peak between 12:00 and 20:00 LST, is evident in both the gauge-based and CMORPH data (Fig. 5). The datasets agree well with each other at each surface station, except that CMORPH data exhibit larger peak values at the red and green stations. The four gauge-based stations in blue have a much weaker daytime peak. These stations, however, have an apparent nocturnal peak, whereas other stations do not exhibit a nocturnal peak. The nocturnal precipitation is possibly attributable to the convergence between the low-level prevailing wind and downhill jet circulations, which are to be examined with the numerical simulations in Sect. 4. The average over all stations (thick black line in Fig. 5) also exhibits an obvious diurnal cycle.

The horizontal distribution of precipitation was analyzed using the CMORPH data (every $3 \mathrm{~h}$, except that 17:00 LST was used, as it is the strongest rainfall time in CMORPH data in Fig. 6) along with the perturbation surface wind at 


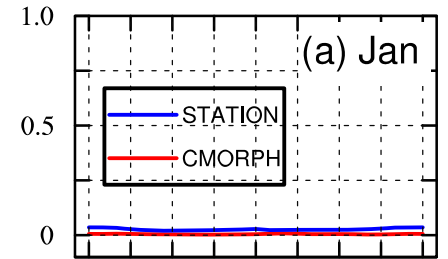

$\begin{array}{lllllllll}06 & 09 & 12 & 15 & 18 & 21 & 00 & 03 & 06\end{array}$

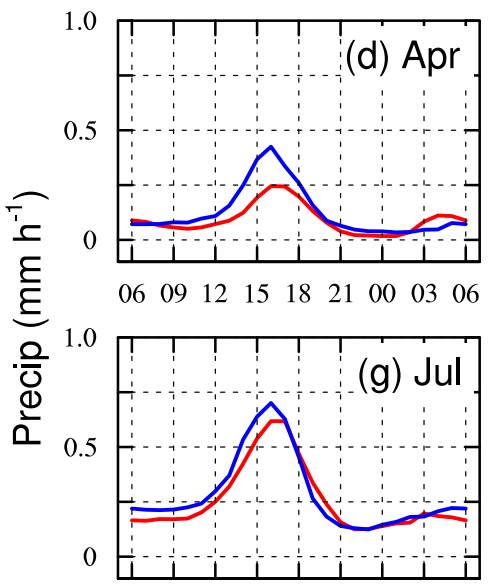

$\begin{array}{lllllllll}06 & 09 & 12 & 15 & 18 & 21 & 00 & 03 & 06\end{array}$

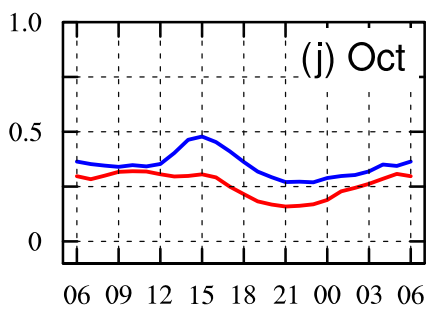

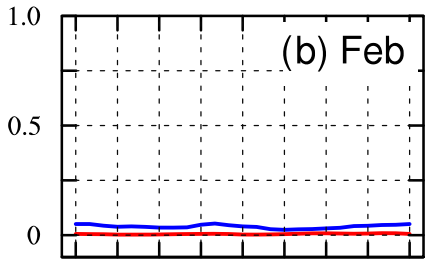

$\begin{array}{llllllllll}06 & 09 & 12 & 15 & 18 & 21 & 00 & 03 & 06\end{array}$

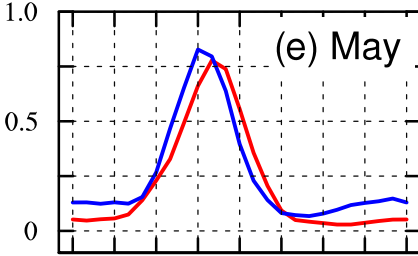

$\begin{array}{llllllllll}06 & 09 & 12 & 15 & 18 & 21 & 00 & 03 & 06\end{array}$

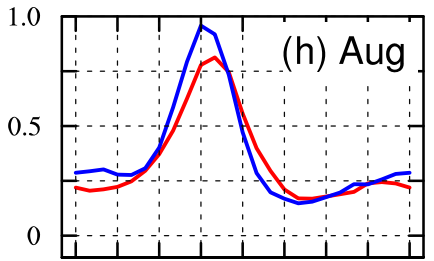

$\begin{array}{lllllllll}06 & 09 & 12 & 15 & 18 & 21 & 00 & 03 & 06\end{array}$

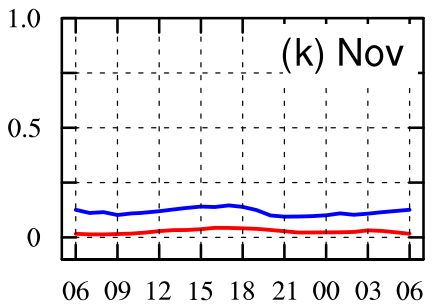

Time (LST)

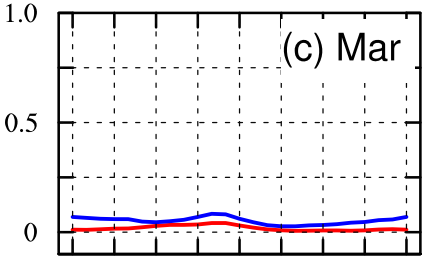

$\begin{array}{llllllllll}06 & 09 & 12 & 15 & 18 & 21 & 00 & 03 & 06\end{array}$

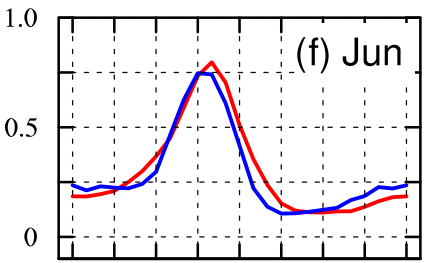

$\begin{array}{llllllllll}06 & 09 & 12 & 15 & 18 & 21 & 00 & 03 & 06\end{array}$

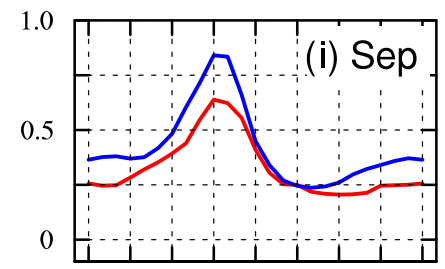

$06 \quad 0912 \quad 15182100 \quad 03 \quad 06$

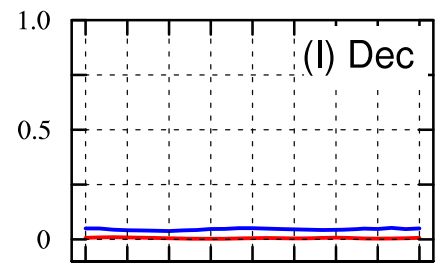

$06 \quad 0912 \quad 1518 \quad 2100 \quad 03 \quad 06$

Figure 3. Average station rainfall accumulations obtained from gauges (blue) and CMORPH (red) in each month.

gauge stations, which was obtained by subtracting the daily mean from the total wind to highlight the diurnal cycle. The precipitation averaged over all times shows that the precipitation mainly appears in the northeast on the lee side of the mountainous area (Fig. 6a). The gauge-based stations with significant diurnal cycle (in red dots) are located over the heaviest rainfall region, while the gauge-based stations with nondistinctive diurnal features (in blue dots) are located in the weakest precipitation area. Hourly variation in precipitation shows that there is little precipitation over the island in the early to mid-morning (00:00 to 09:00 LST), which is on average less than over the surrounding ocean. At 06:00 LST, the perturbation surface wind at the gauge stations has an offshore direction in the coastal area, a signature of nighttime land breeze (Fig. 6b). Three hours later at 09:00 LST, the perturbation wind strengthens and turns to the right of its previous direction, particularly along the coast (Fig. 6c). At 12:00 LST, the wind changes to an onshore direction, representing the beginning of a sea breeze along with the start of weak inland precipitation where the sea breeze converges (Fig. 6d). In the next several hours (Fig. 6e and $f$ ), the rainfall intensifies rapidly, reaching its peak at around 17:00 LST. The heaviest precipitation is concentrated in the northeast of the island, corresponding to strong convergence of the sea breeze (Fig. 6f). The precipitation dissipates rapidly thereafter and there is almost no precipitation by 03:00 LST (Fig. 6g-i). The perturbation wind also weakens quickly and turns to offshore along the northern coast. The magnitude of the perturbation wind is close to zero over the island at 21:00 LST (Fig. 6g). The land breeze intensifies slowly and nocturnal precipitation initiates along the southeastern coast of the island (Fig. 6h). The nocturnal precipitation intensifies until its peak and expands to a larger area at 03:00 LST, while the precipitation decreases to a minimum (near zero) over the central island (Fig. 6i).

Although the analyses on the precipitation and surface wind observation can efficiently reflect general features of the diurnal rainfall variation and the LSB, they cannot be 

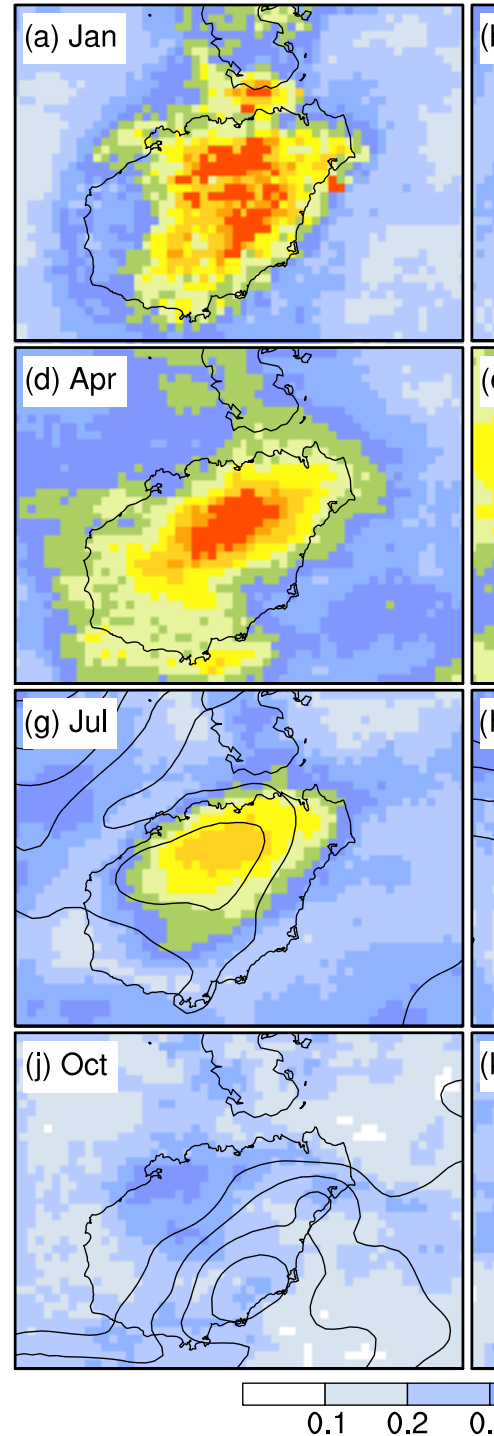
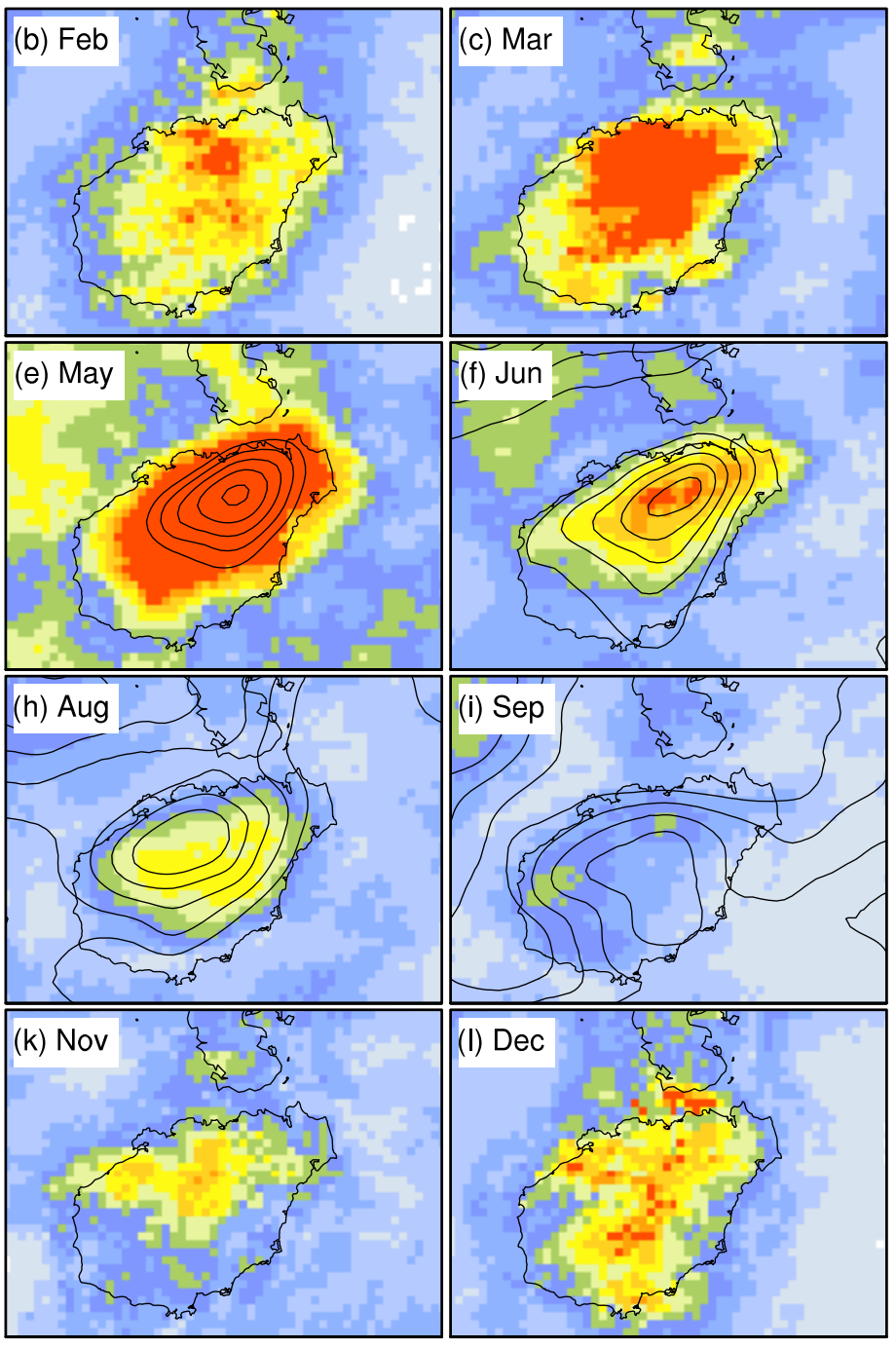

Figure 4. Fraction of the total precipitation that can be attributed to the diurnal cycle by month (shading), along with average hourly precipitation accumulations (black contours every $0.05 \mathrm{~mm}$, starting at $0.25 \mathrm{~mm}$ ).
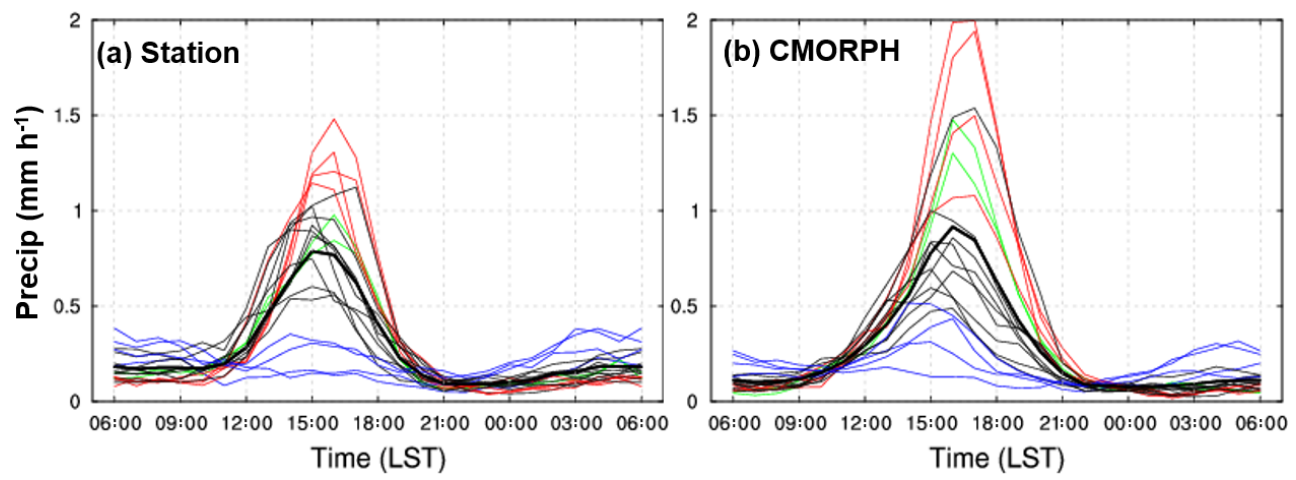

Figure 5. Average rainfall accumulations by hour in May and June (a) from rain gauges and (b) derived from CMORPH. 


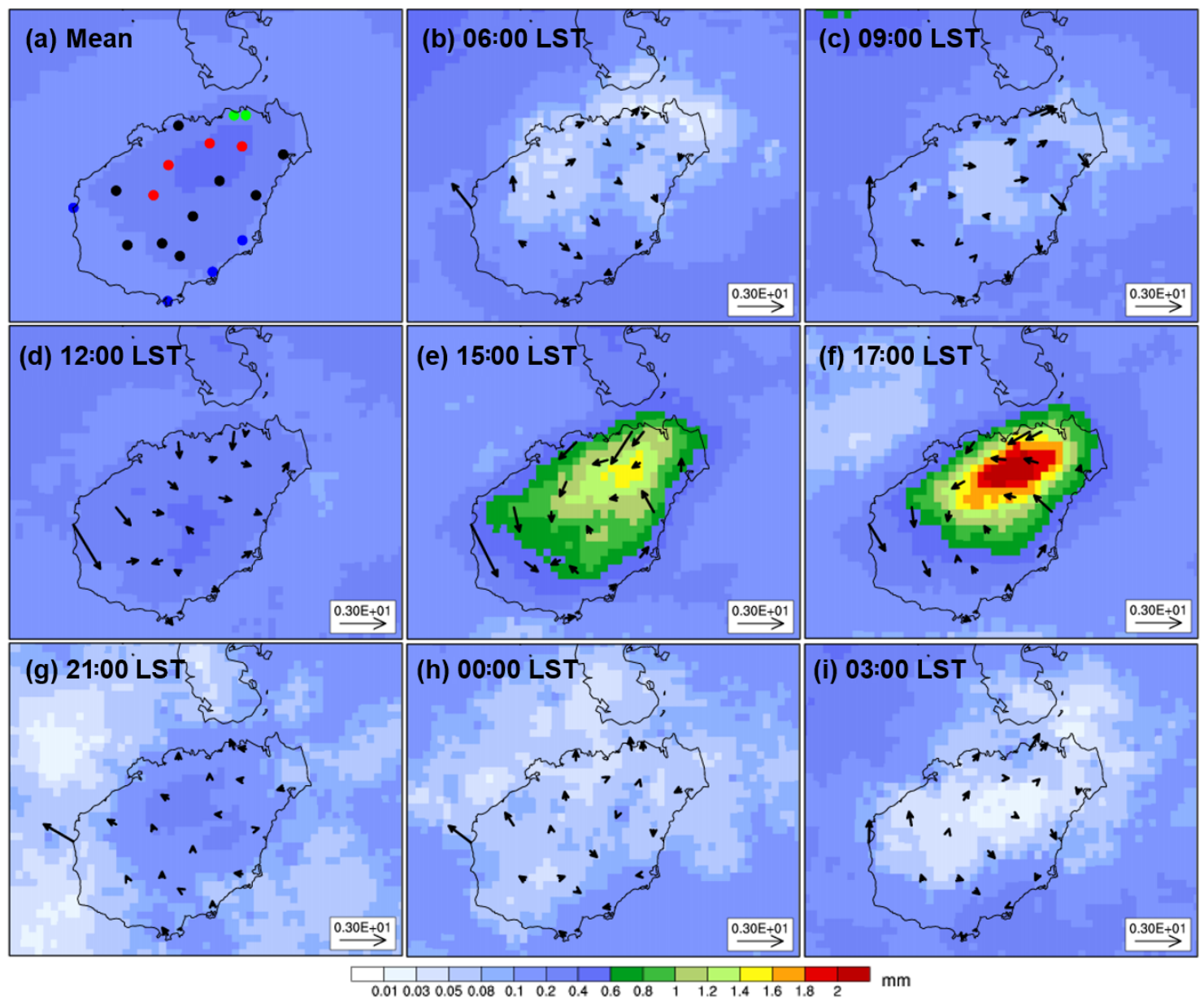

Figure 6. Ten-year average of hourly rainfall accumulations at $3 \mathrm{~h}$ intervals for May and June derived from CMORPH (shading) except 17:00 LST is used as it is the strongest rainfall time in the CMORPH observation. Three-year average wind velocity (vectors) is also shown. Rain gauge locations are indicated in (a).

used to examine the detailed dynamics and thermodynamics processes of the diurnal precipitation cycle and the related LSB over the tropical island. The 3-dimensional structures of the LSB, as well as the mechanism of how the LSB triggers and enhances the diurnal precipitation cannot be resolved by the surface observation alone. These aspects were examined using a numerical model, as discussed in the next section.

\section{Numerical simulation results}

\subsection{The simulated diurnal cycle and the influence of the orography}

The REAL simulation reproduces the diurnal cycle of precipitation and the associated LSB. The diurnal variations in the $2 \mathrm{~m}$ temperature, $2 \mathrm{~m}$ temperature tendency, and precipitation averaged over the last 26 days of the WRF simulations and all stations over the island (Fig. 7) show generally good agreement with the observations, except for slightly higher peak values of simulated $2 \mathrm{~m}$ temperature and simulated precipitation (cf. Fig. 7a and b). The overall process of the diurnal variation over the island was well simulated, suggesting that the chosen setup of WRF-ARW has the ability to capture the radiative effect due to solar insolation well. The surface temperature begins to increase at 06:00 LST and peaks at 13:00 LST, coincident with the increase of solar heating. With the rainfall evaporation cooling rate becoming larger than the solar heating rate and/or the radiative cooling later on, the temperature starts to decrease thereafter. After sunset, the temperature drops continuously, reaching its minimum near 06:00 LST.

The horizontal distribution of precipitation averaged in REAL (Fig. 8a), especially the location of the high precipitation area, also has reasonably good agreement with that of the CMORPH data at all hours (Fig. 6a), although the simulated precipitation is somewhat larger. The area of heavy precipitation at the center of the island is well captured by the WRF simulation, although the magnitude is noticeably overesti- 

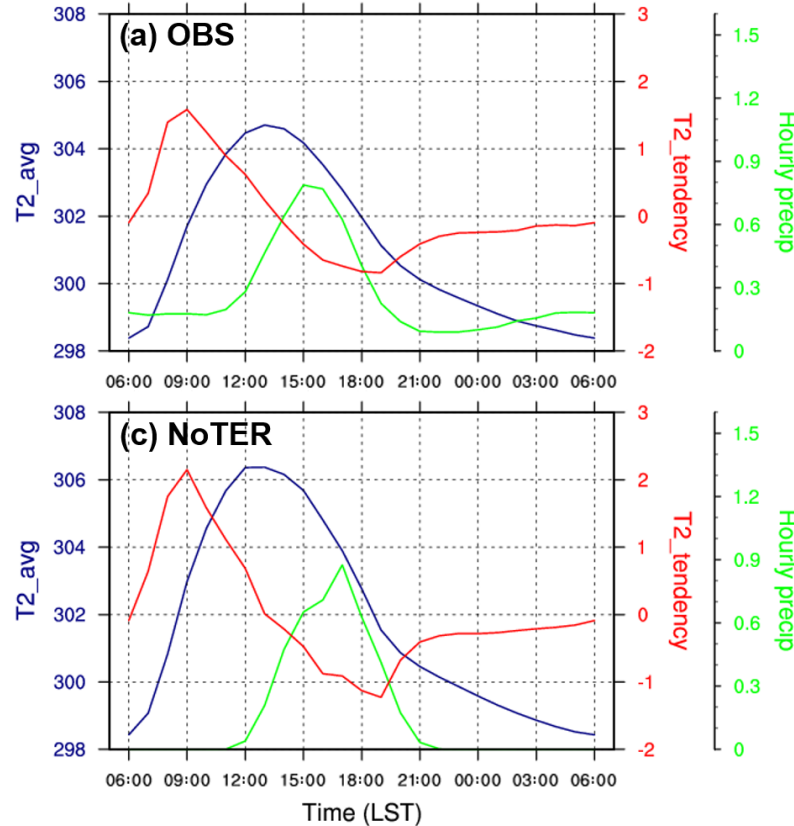

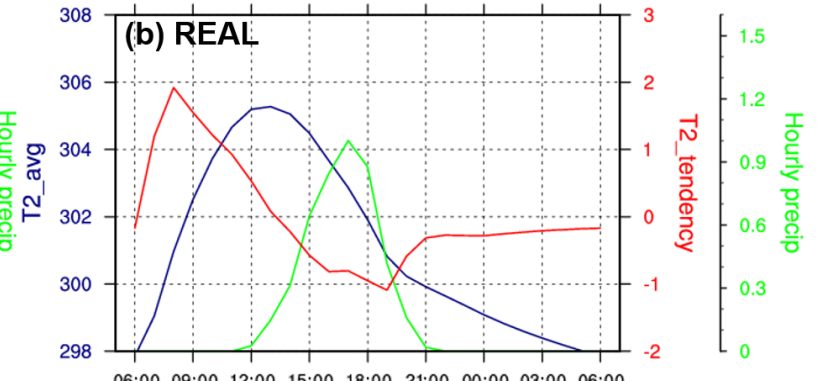

06:00 09:00 12:00 15:00 18:00 21:00 00:00 03:00 06:00

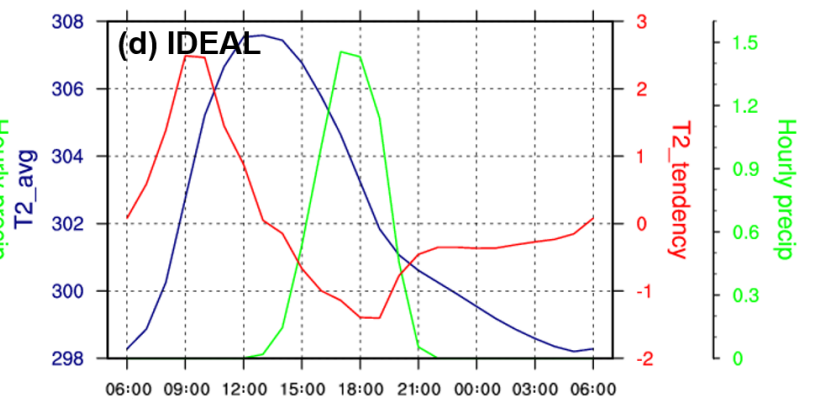

Time (LST)

Figure 7. The average of $2 \mathrm{~m}$ temperature (T2_avg), $2 \mathrm{~m}$ temperature tendency (T2_tendency, temperature difference between two neighboring hours), and hourly rainfall accumulation over the island based on (a) gauge observations, (b) the REAL experiment, (c) the NoTER experiment, and (d) the IDEAL experiment. Horizontal colored lines indicate means over all hours.

mated. The diurnal precipitation cycle is also well revealed by the variation in the horizontal distribution of the simulated precipitation, although with a slightly larger magnitude and a $1 \mathrm{~h}$ delay in peak time. The evolution of the simulated surface perturbation wind (on the second-lowest model level for horizontal wind, which is the 0.994-sigma level, about $50 \mathrm{~m}$ above the surface) is also consistent with the observation despite some discrepancy in magnitude (Figs. 6 and 8), suggesting that the LSB is well captured as well. However, the evening rainfall along the southern coast is missing, which is likely because the resolution we used in this study was still too coarse to resolve the convection over the southern coast or the physical process was so complex that the model is unable to represent it for now.

The results of the NoTER experiment (with removal of island orography) are highly consistent with those of REAL in terms of both the magnitude and timing of each variable averaged over the whole analysis period and at all stations (Fig. 7b and c). Similar results are also found in the horizontal distribution features (Figs. 8 and 9). Neither the pattern nor the magnitude is altered meaningfully between the two simulations. These results suggest that the diurnal cycle characteristics are not sensitive to the orography over Hainan Island, although many previous studies demonstrated that the orography can play an important role in the precipitation over other islands (Sobel et al., 2011; Hassim et al., 2016; Barthlott and Kirshbaum, 2013).

In order to simplify the influences of land category and coastline, the experiment IDEAL was constructed with an idealized elliptical island to replace the real Hainan Island in the initial condition. The diurnal variation in the $2 \mathrm{~m}$ temperature (blue), $2 \mathrm{~m}$ temperature tendency (red), and hourly accumulated precipitation (green) in IDEAL (Fig. 7d) are nearly identical to those in REAL (Fig. 7b) and the station observation (Fig. 7a), except for their larger magnitudes, which could be related to the modified surface land category and the smoothed ellipsoidal coastlines. The diurnal variations in the hourly accumulated precipitation and perturbation wind on the second-lowest model level for horizontal wind (Fig. 10) in the IDEAL experiment show that the timing of the LSB transitions and the precipitation location are quite similar to those in REAL and the observation, with much smoother distribution in the horizontal perturbation wind and precipitation over the island. The relationship between the diurnal variation in precipitation and LSB will be further examined in detail based on the results of IDEAL in the next section.

\subsection{Diurnal variation in precipitation and the related LSB in IDEAL}

The mean fields averaged over all hourly model output times during the last 26 days of the simulation depict a southerly low-level prevailing flow over the whole domain, which transports warm moist air to the island from the South China Sea (Fig. 10a). Greater moisture appears in the northern island over the heavy precipitation area under the influence of southwesterly low- to mid-level flow ( $850 \mathrm{hPa}$, Fig. 11a). 

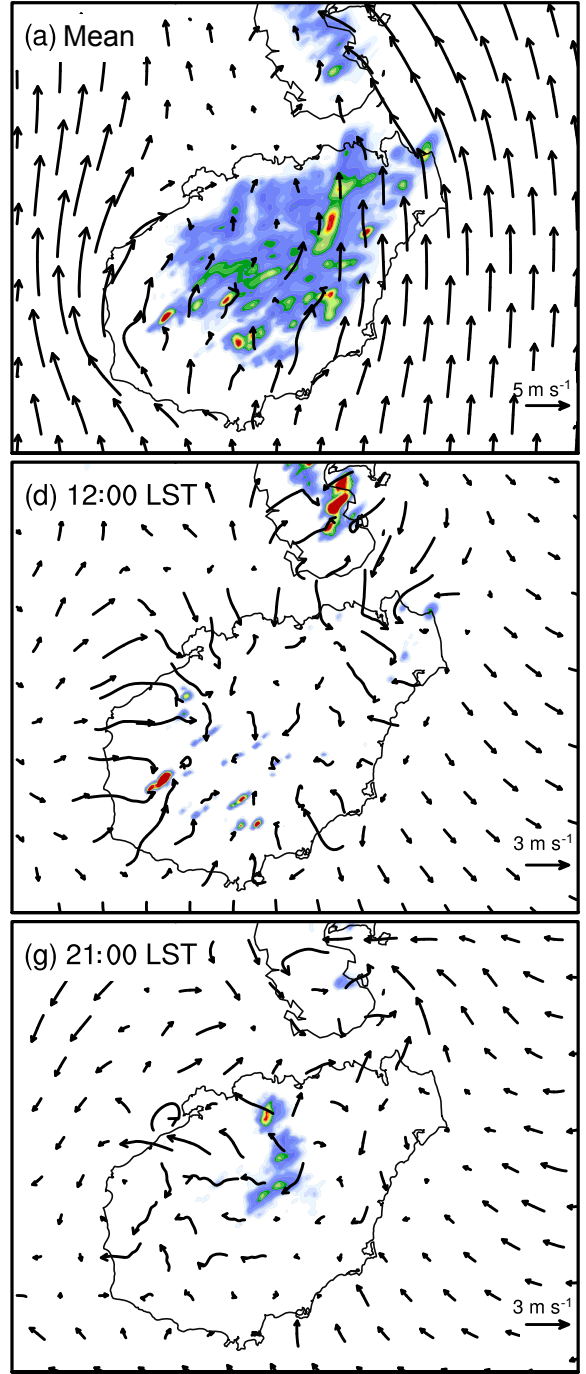
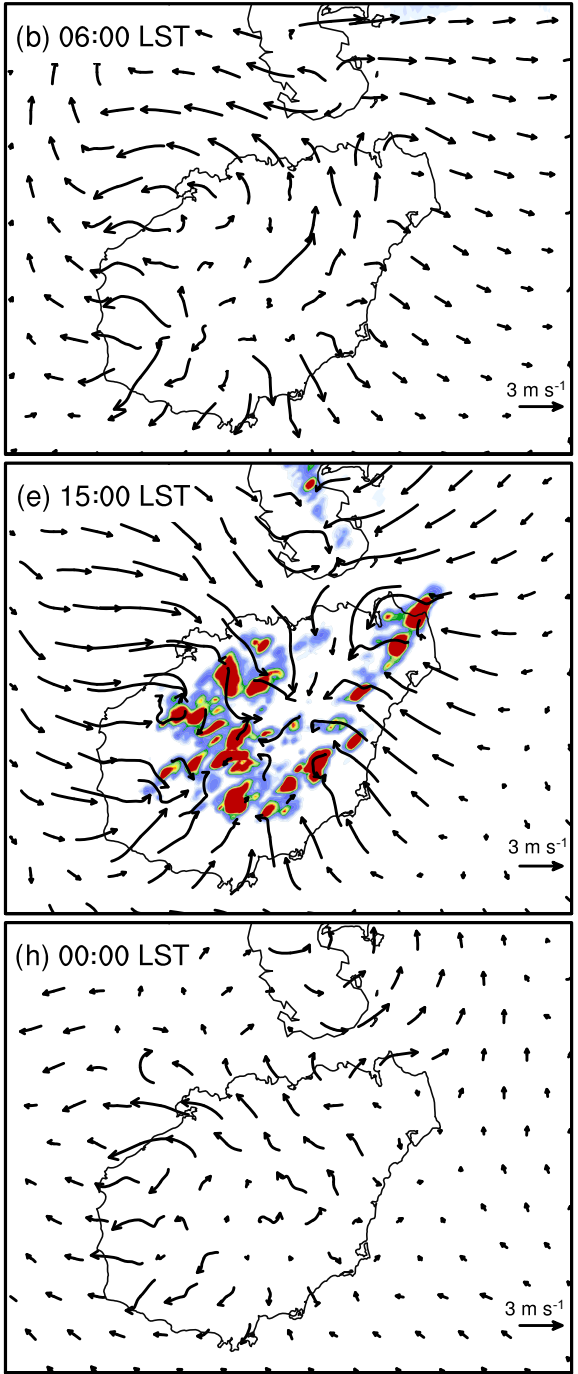
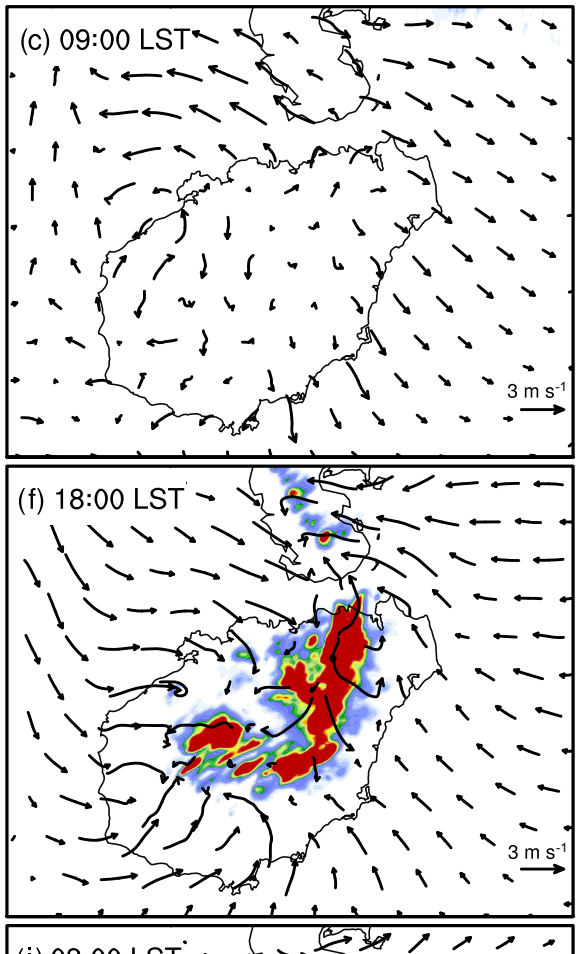

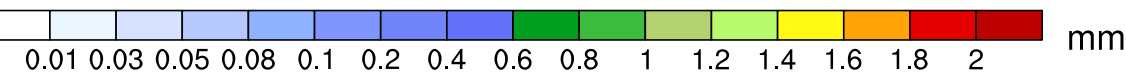

Figure 8. Hourly precipitation accumulation (shading) and average perturbation wind (vectors) on the second-lowest model level for horizontal wind in the REAL experiment every $3 \mathrm{~h}$. The averages over all hours are shown in (a).

A higher surface temperature appears over the southern side than on the northern side (Fig. 12a).

Based on the different phases of surface temperature and perturbation wind, we divided the diurnal cycle process into four stages to elucidate the mechanisms in each stage. The stages are (1) the establishment of a sea breeze (06:00-12:00 LST), (2) the peak sea breeze and peak precipitation (12:00-18:00 LST), (3) the establishment of a land breeze (18:00-00:00 LST), and (4) the peak land-breeze phase (00:00-06:00 LST). More detailed analyses will be focused on the two middle stages. These are the most complicated stages but are also the most pertinent to the heavy diurnal precipitation (and are therefore the most interesting).

\subsubsection{Stage 1. Establishment of a sea breeze (06:00-12:00 LST)}

This stage commences with the onset of surface heating following sunrise. Because ocean and land have different heat capacities, the island is heated faster than the surrounding ocean. The temperature gradient between the island and the surrounding ocean gradually reverses from offshore to onshore, which results in the weakening and demise of the land breeze and the establishment of a sea breeze over the island.

In early morning hours when the sun is just about to rise, surface air temperatures over the island attain their lowest readings, with air temperatures being a few degrees lower than over the surrounding ocean (Fig. 12b). Owing to persistent solar heating, the surface air temperature over most 

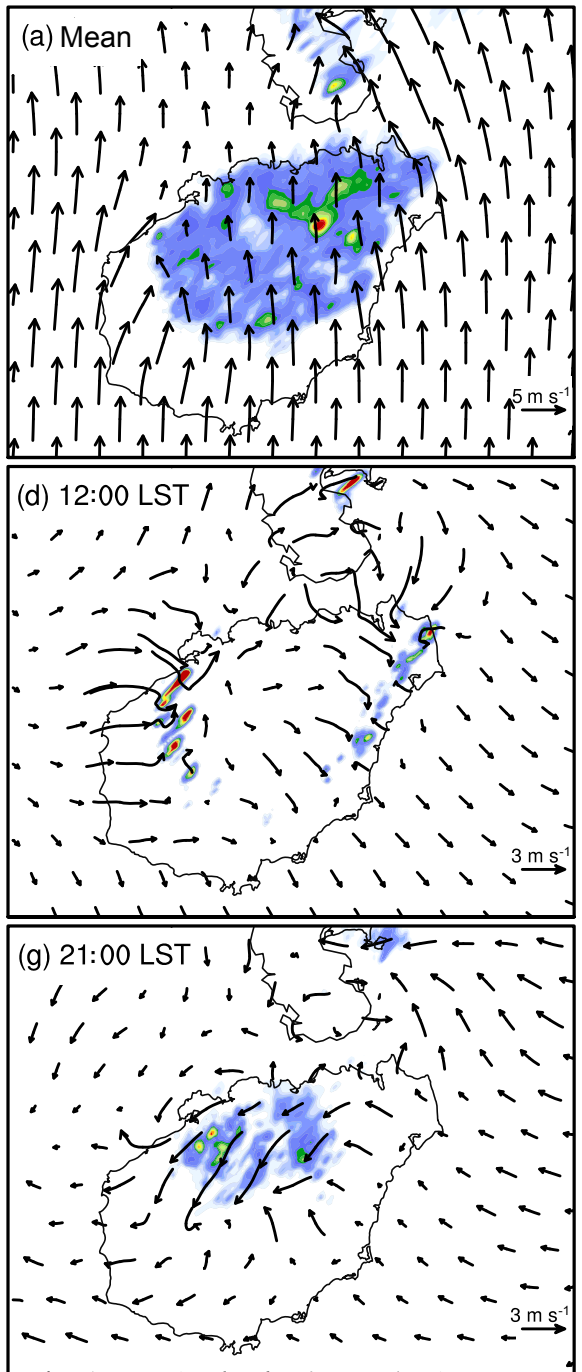
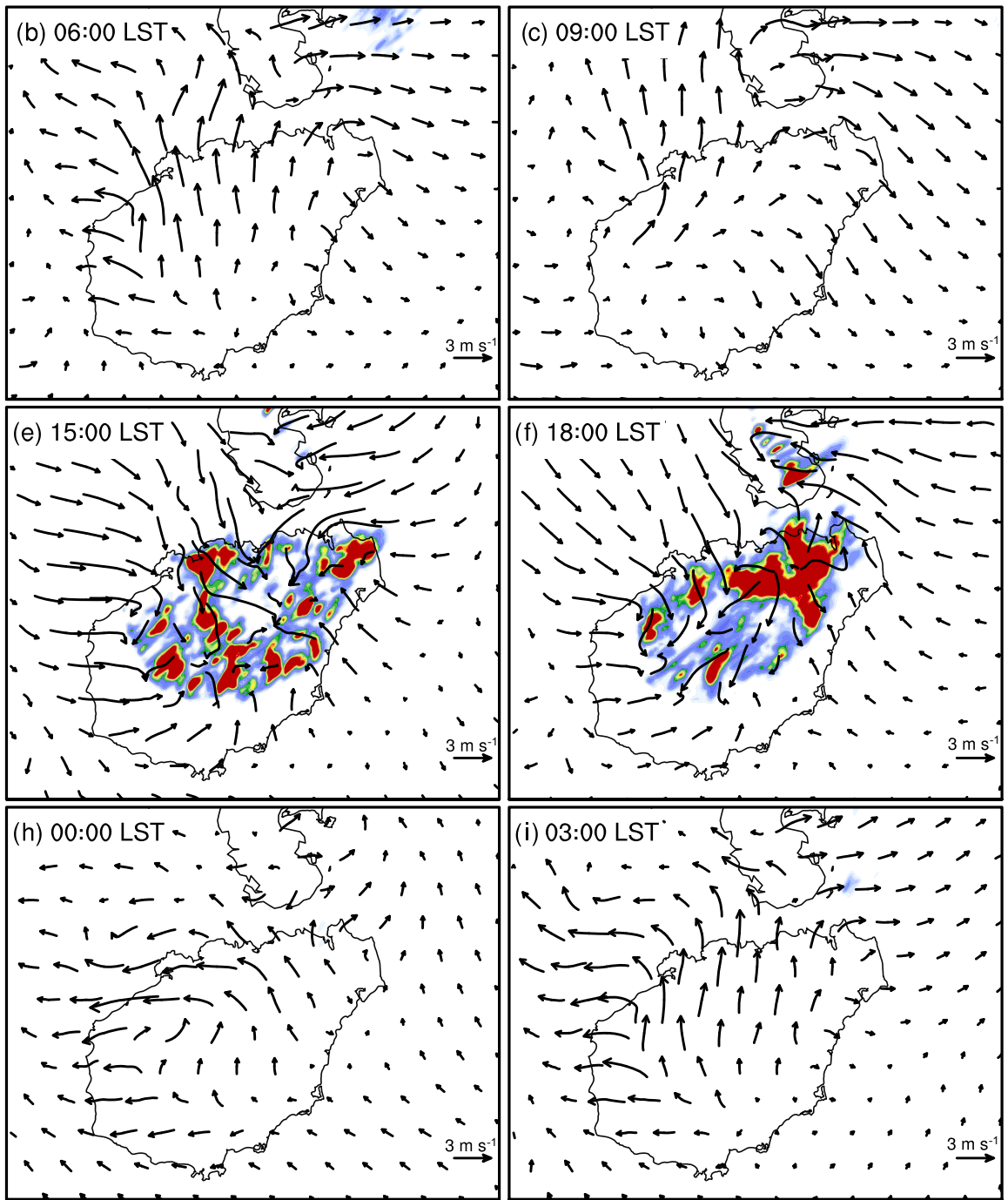

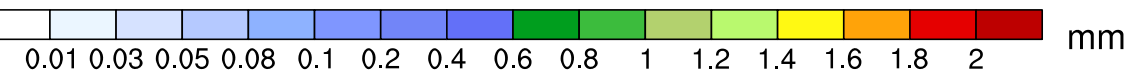

Figure 9. As in Fig. 8 but for the NoTER experiment.

parts of the island exceeds the ocean by 09:00 LST (Fig. 12c). Meanwhile, the surface air temperature gradient is directed from offshore to onshore, although the land breeze still persists over the island at this time.

The local rate of warming is inhomogeneous over the island. The surface temperatures in the northeastern part of the island are considerably lower than in other regions where the temperatures surpass the surrounding ocean by 09:00 LST. The slower warming in the northeastern part of Hainan Island is likely due to the morning fog or cold pool air (Fig. 13b) that commonly forms within the area humidified (Fig. 14b) by late-afternoon precipitation on the preceding day. The cloud over the area attenuates solar radiation and subsequently slows the local warming. Moreover, positive horizontal temperature advection exists over the southern island
(Fig. 15a and b), which helps to increase the temperature faster over the area. The sea breeze begins to develop along the southwestern coastline owing to the weakest land breeze and the highest warming rate, while other areas of the island are still under the control of the land breeze with an offshore temperature gradient (Fig. 12c). Two land-breeze circulations (LBCs) appear clearly in the vertical direction below $3 \mathrm{~km}$ along the coast of the island at 06:00 LST (Fig. 14b). The southern LBC recedes quickly with the reversal of the temperature gradient at around 09:00LST, while the other LBC remains distinct (Fig. 14c).

By 12:00 LST, the temperature gradient reverses to the onshore direction, while the sea breeze has fully established along the entire coastline (Fig. 12d). The warming speeds are not even over the island, with a much faster warming 

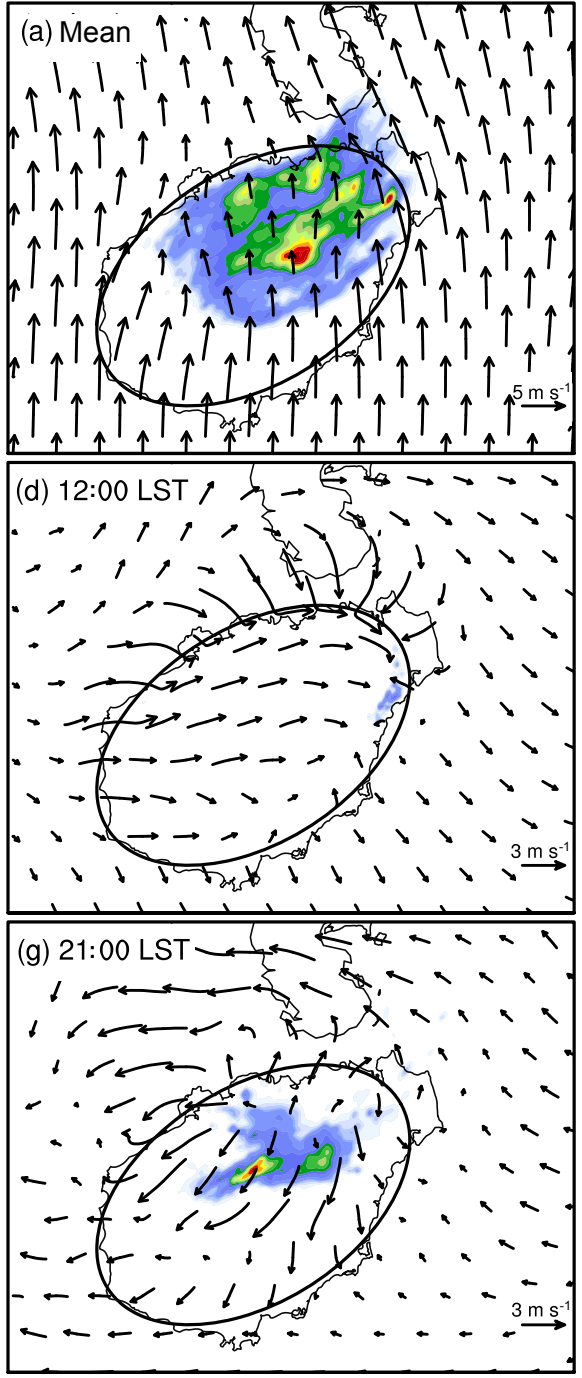
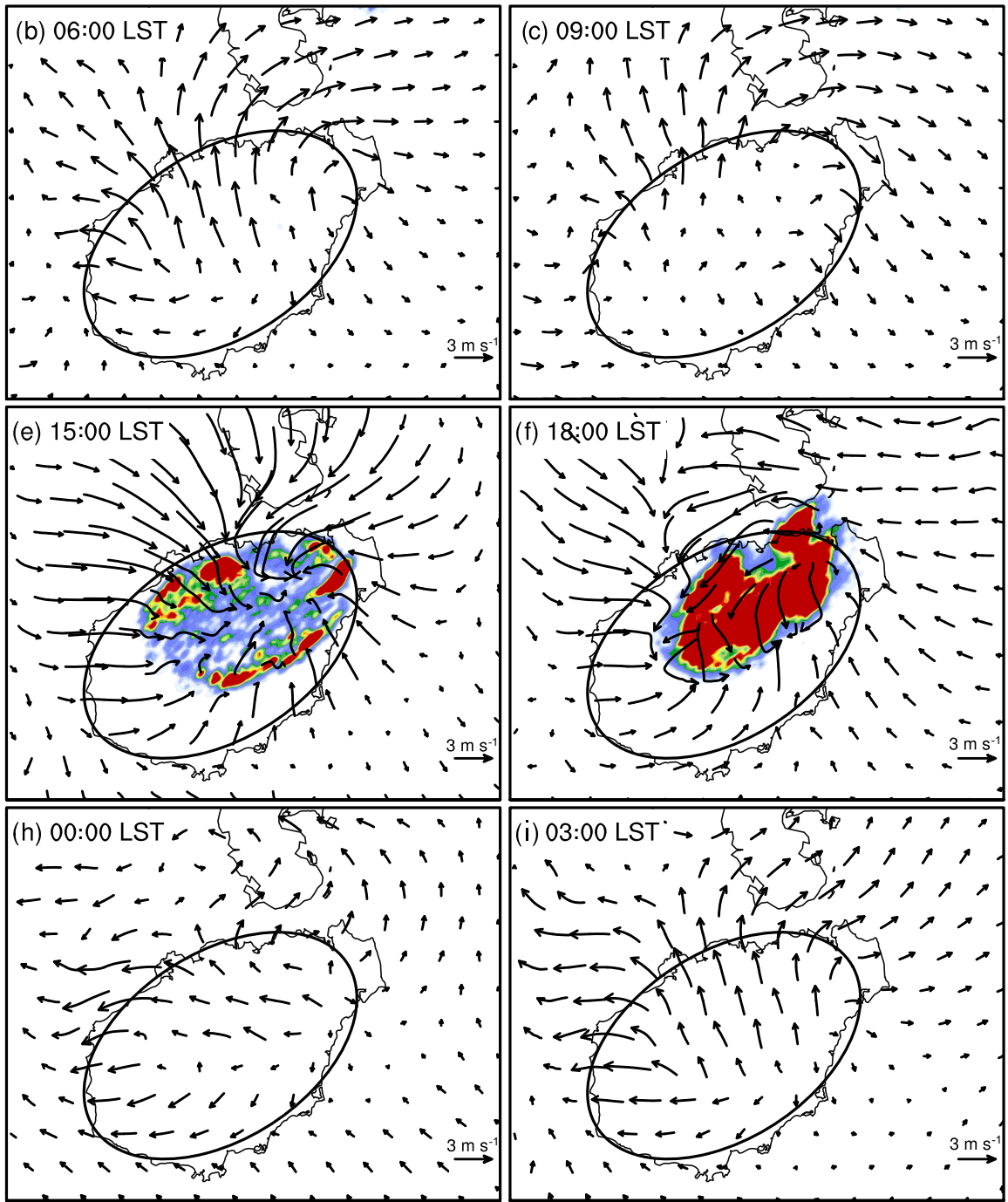

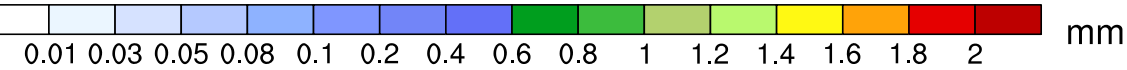

Figure 10. As in Fig. 8 but for the IDEAL experiment.

speed over the northern island than over the southern island, which is a result of a high negative horizontal temperature advection over the southern island along the coastlines (Fig. 15d). A sea-breeze front appears at the leading edge of the sea breeze along the coastline, particularly along the northernmost coast where the maximum near-surface temperature gradient lies (Fig. 12d). At the same time, copious water vapor is transported inland from the ocean owing to the low-to-mid level prevailing wind (Fig. 11d) and upward motions (Fig. 14d). Clouds initially form along the sea breeze (Fig. 13c) and subsequently produce rainfall (shaded in Fig. 10d and green lines in Fig. 13d). Noticeably, more rapid warming during this period happens over the northwest of the island, while it is much slower over the other areas
(Fig. 12d), which is because of the horizontal gradient and advection of the temperature over the whole island (Fig. 15).

\subsubsection{Stage 2. Peak sea breeze and peak precipitation (12:00-18:00 LST)}

Surface temperature is at a maximum from 12:00 to 14:00 LST over most of the island, then decreases rapidly owning primarily to the development of precipitation (which reaches its diurnal maximum during this period) and associated evaporative cooling. Besides, surface temperature is also controlled by other processes, such as surface heat fluxes, both shortwave and long wave radiative processes, diffusion in the soil, etc. The sea breeze also reaches its peak intensity in the 12:00-14:00 LST time period. 

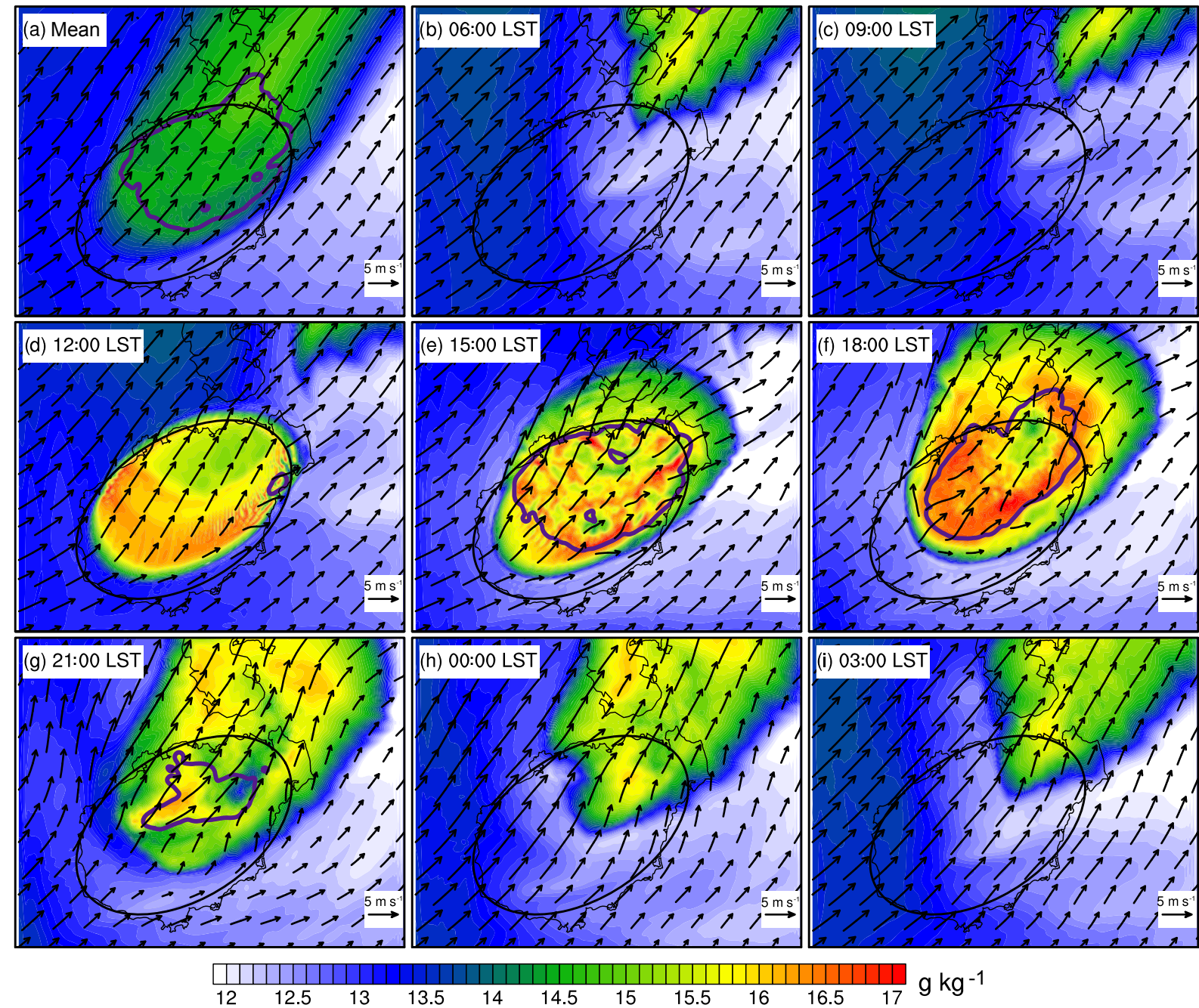

Figure 11. Water vapor mixing ratio (shading) and horizontal wind (vectors) at $850 \mathrm{hPa}$, and hourly precipitation accumulations $>0.1 \mathrm{~mm}$ (thick purple contours) (b-i) every $3 \mathrm{~h}$ and (a) averaged over all times.

At 15:00 LST, surface temperature decreases over the rainfall area owing to evaporation cooling and slightly increases over other areas because of continuous solar heating (Fig. 12e). There is significant enhancement in upward motions in the low-to-middle troposphere (Fig. 14e). The sea breeze reaches its peak strength and greatest inland penetration (Fig. 12e). Two distinct sea-breeze circulations (SBCs) are clearly seen in the vertical cross section, with the stronger one over the northern flank of the island (Fig. 14e). Moist air is transported from the ocean to the island persistently by the deep southwesterly prevailing wind throughout the lower troposphere (Fig. 11e), while low-level convergence of moist air generates strong updrafts, which results in an increase of the moisture over the mid-levels (Fig. 14e). These factors favor the development of deep convection over the northern flank of the island. As a result, precipitation increases significantly along the sea-breeze front (Fig. 10e).
By 18:00 LST, the strongest rainfall falls over the island (Fig. 10f) owning to the strongest low-level convergence and subsequent lifting of warm moist air (Fig. 14f). The seabreeze fronts move further inland and collide with each other near the center of the island (Fig. 12f), with a deep layer of moisture over the northern side of the island that fuels the strong precipitation (Figs. 11f and 14f). Cold pools form owing to the evaporation cooling of the precipitation, contributing to the propagation and enhancement of the precipitation, which will be further examined with two other sensitivity experiments in the next section. The precipitation pattern (Fig. 10f) exhibits a horseshoe shape aligned with the prevailing wind direction, which is similar to the result of the urban heat island study by Han and Baik (2008). 

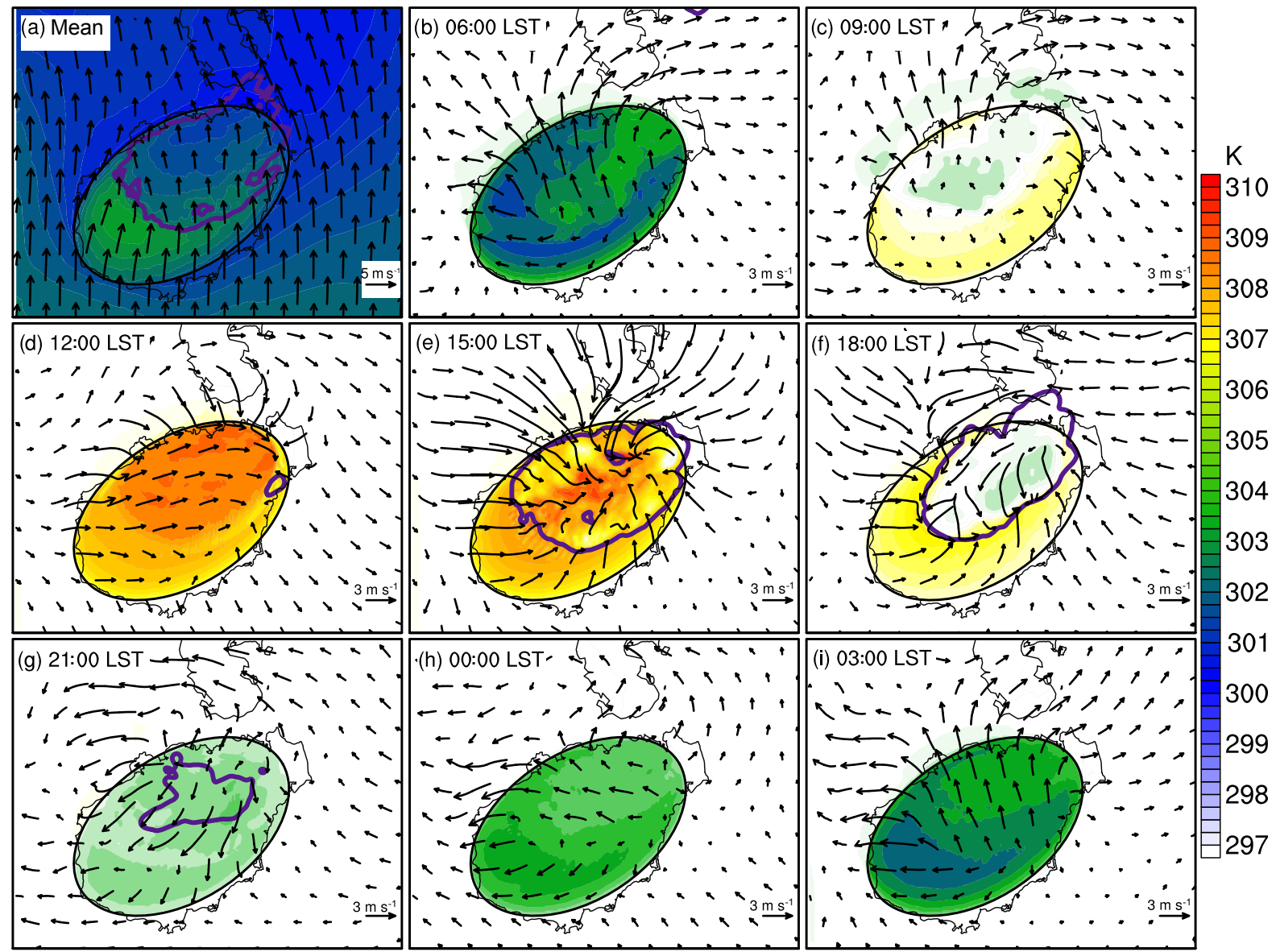

300

299

298

$\begin{array}{lllllllllllllllllll}-8 & -7 & -6 & -5 & -4 & -3 & -2 & -1 & 0 & 1 & 2 & 3 & 4 & 5 & 6 & 7 & 8 & K\end{array}$

Figure 12. (a) $2 \mathrm{~m}$ mean temperature (shading) and horizontal wind (vectors) on the second-lowest model level for horizontal wind; (b-i) $2 \mathrm{~m}$ mean temperature perturbation (shading) and mean perturbation horizontal wind (vectors) on the second-lowest model level every $3 \mathrm{~h}$. The right color bar is used for (a).

\subsubsection{Stage 3. Establishment of a land breeze (18:00-00:00 LST)}

During this period, the convection quickly dissipates and the sea breeze is replaced by a land breeze (Fig. $10 \mathrm{~g}$ and h) after sunset. The surface temperature decreases continuously throughout this stage over the island. The rate of temperature decrease is fastest in the first several hours, reaching around $-1.5 \mathrm{Kh}^{-1}$ at 18:00-19:00 LST (red line in Fig. 7d) due to the sudden loss of solar heating. The horizontal temperature gradient begins to reverse, which eventually leads to the establishment of the land breeze (Fig. 12g and h). By 21:00 LST, approximately $2 \mathrm{~h}$ after sunset, temperature over the island decreases rapidly, both at the surface (Fig. 12g) and throughout the boundary layer. Meanwhile, subsidence becomes dominant over the island (Fig. 14g). The subsidence dries the lower levels and rainfall ceases over the whole island (Fig. 13g).
By 00:00 LST, with the continuously decreasing temperature and amplifying of the offshore temperature gradient, the land-breeze circulations are well established, in particular across the shore of the northern island (Fig. 14h). Further drying is seen at middle-to-low levels as the much stronger downward flow occurs over the island, which transports dry air from aloft to the mid-to-low levels (Figs. 11h and 14h). At the same time, under the influence of the prevailing wind, much more moist air is concentrated over the northern island, so the moisture over the northern island is much moister than over the southern island. Clouds vanish quickly and precipitation dissipates almost completely by this time.

\subsubsection{Stage 4. Peak land breeze (00:00-06:00 LST)}

The land breeze reaches its maximum intensity during this period. Nighttime radiative cooling results in the minimum temperature being attained at approximately 05:00 LST. From 00:00 to 03:00 LST, the land breeze intensifies rapidly 
(a) 03:00 LST

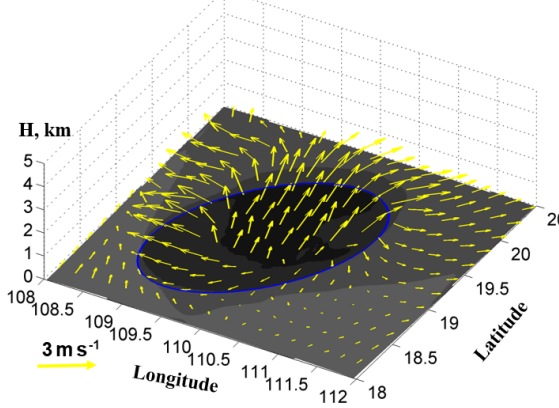

(d) 12:00 LST

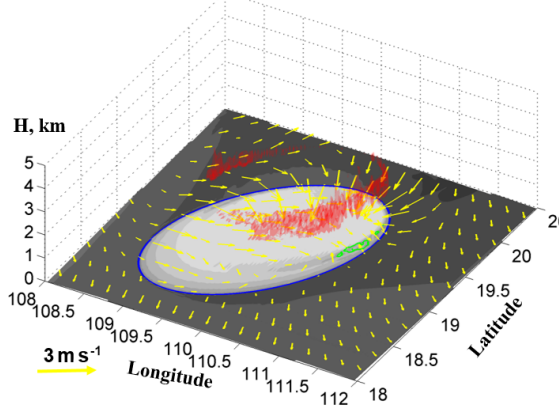

(g) 21:00 LST (b) 06:00 LST

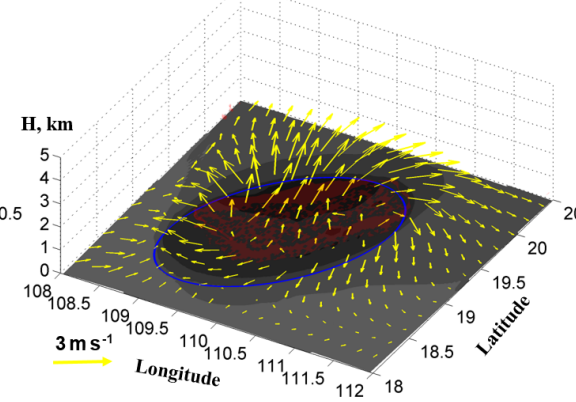

(e) 15:00 LST

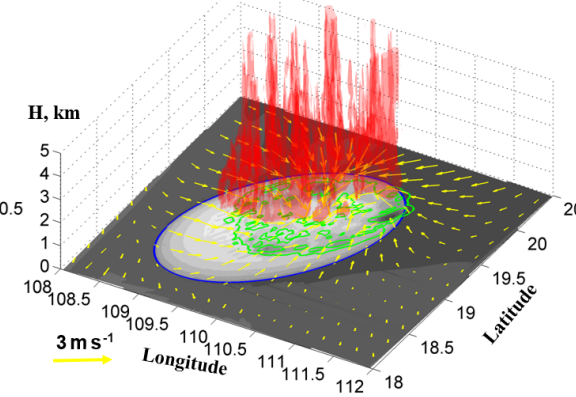

(h) 00:00 LST (c) 09:00 LST

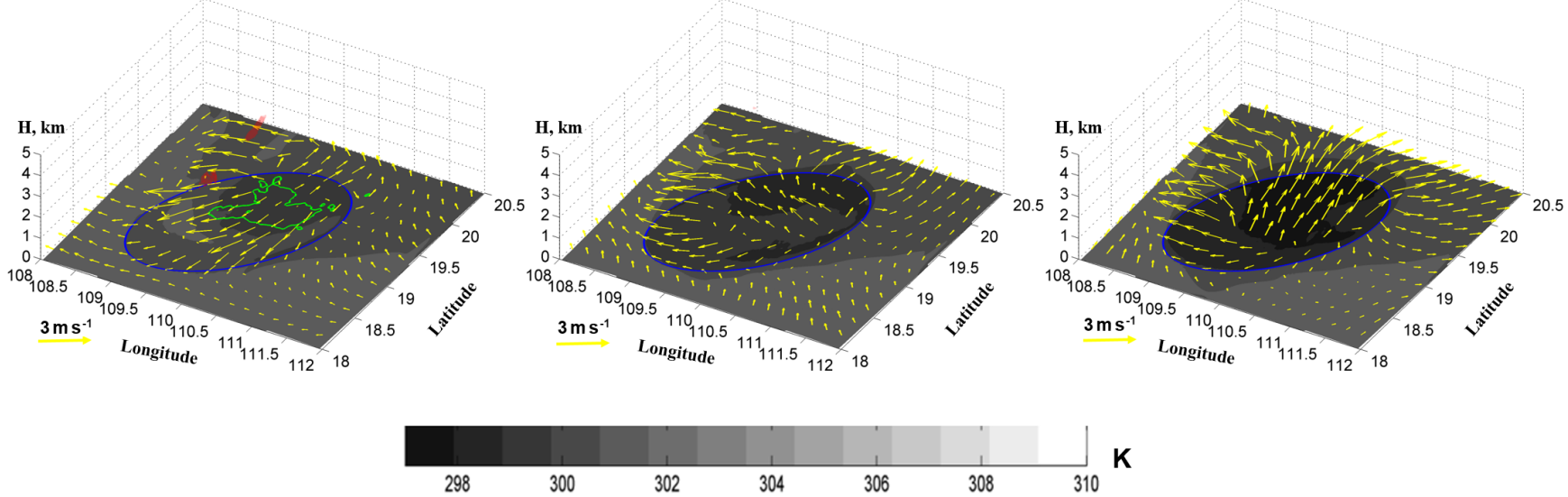

Figure 13. Cloud water mixing ratio (red shading), $2 \mathrm{~m}$ temperature (grey shaded), perturbation horizontal wind on the second-lowest model level for horizontal wind (yellow vectors), and hourly precipitation accumulation (green contour lines) every $3 \mathrm{~h}$.

along the northwestern coast, becoming nearly perpendicular to the coastline and parallel with the low-level prevailing wind as the surface temperature over land decreases (Fig. 12i). Two LBCs are evident in the vertical cross section (Fig. 13i). Subsidence extends over the entire island (Fig. 14i). The peak land breeze is established at 06:00 LST (Fig. 12b). The strong subsidence also leads to further midlevel drying (Fig. 11b). Near the surface, the cooling is associated with an increase in the relative humidity, which induces the formation of low clouds and fog (Fig. 13b).

\subsection{The impacts of latent heating/cooling on LSB and the related rainfall}

Surface temperature in the FakeDry experiment agrees well with IDEAL over the island, which indicates that the solar heating rather than the latent heating/cooling is primarily responsible for the temperature variability. Although the precipitation decreases significantly, light rainfall still occurs in the late afternoon in conjunction with the sea-breeze front, but with an approximate $3 \mathrm{~h}$ delay in convective initiation. The precipitation attains its maximum at 18:00 LST, which along with the peak sea breeze, also lags behind the IDEAL experiment by approximately $3 \mathrm{~h}$. The impact of cold pool 


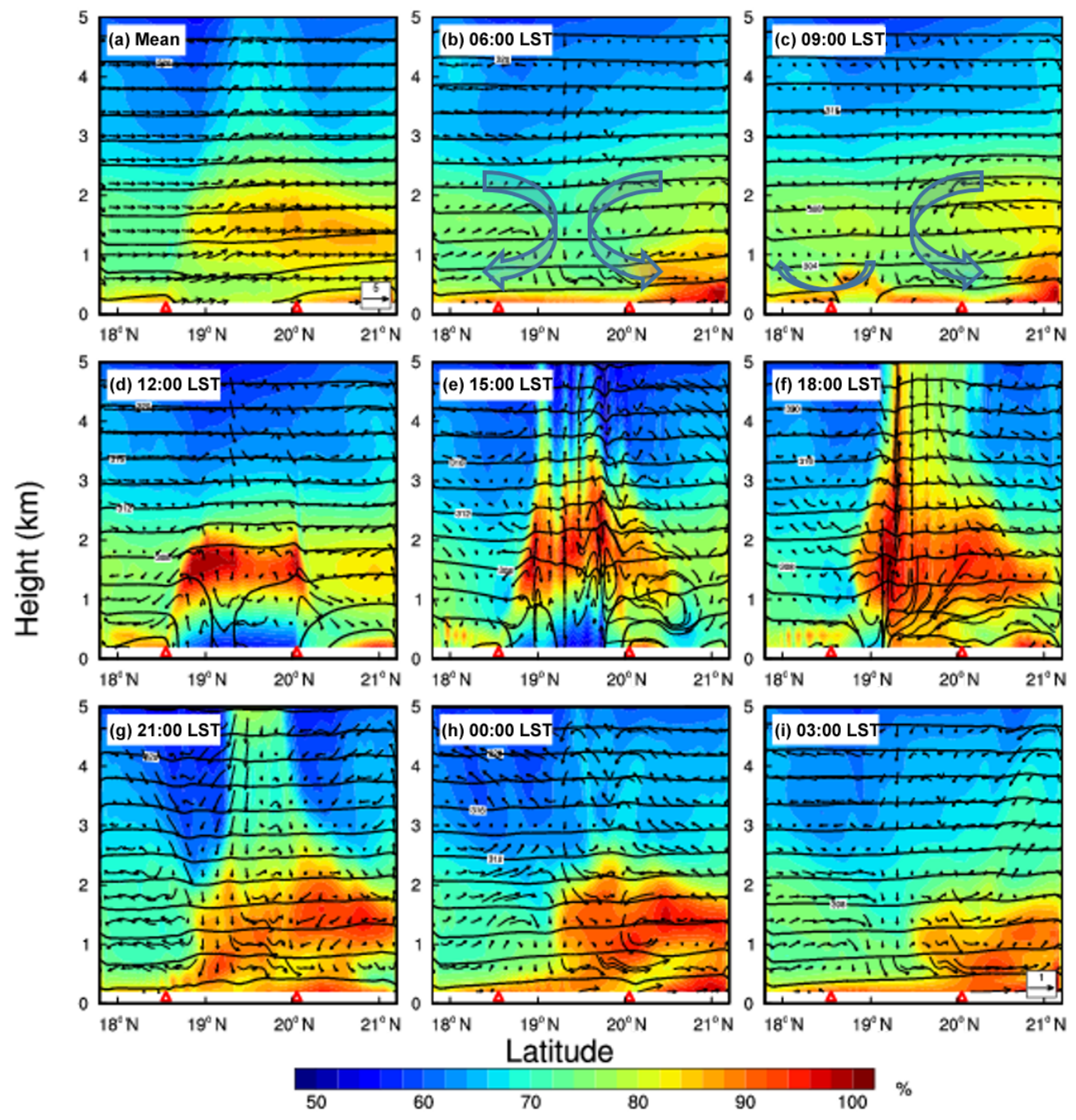

Figure 14. Vertical cross sections of relative humidity (shading), perturbation wind (vectors; the scale of the vertical component is increased by a factor of 5), and temperature (contours) in the south-to-north direction (see red line in Fig. 1) averaged over all hours (a) and at $3 \mathrm{~h}$ intervals $(\mathbf{b}-\mathbf{i})$. The triangles in each panel indicate the edges of the island.

and latent cooling on the sea breeze and rainfall was further examined using the Hovmöller diagrams of zonal wind perturbations on the second-lowest model level for horizontal wind and hourly precipitation along the red line in Fig. 1 for experiments IDEAL, FakeDry and NOVAP (Fig. 16). A weaker sea breeze is observed in the FakeDry experiment than in the IDEAL experiment, while the NOVAP experiment shows the strongest sea breeze. The NOVAP experiment generates much stronger precipitation over the island as the rain evaporation cooling process is turned off. The propagation of the LSB is much slower and the inland propagation distance is much shorter in the FakeDry experiment than in the IDEAL experiment, while the propagation speed in the NOVAP experiment is between the other two experiments, which suggests that the cold pool can accelerate the precipitation over the tropical island. In the NOVAP experiment, the heavy precipitation does not dissipate after 21:00 LST but propagates out of the island into the northeast with the land breeze, indicating that the cold pool plays an important role in dissipating the convection. Moreover, given precipitation varies precisely with the convergence and divergence of horizontal winds owing to LSB in all simulations, it is evident that the LSB is the primary forcing for the diurnal precipitation variability over the island.

The LSB circulations in the FakeDry experiment are similar to those in the IDEAL experiment, and consistent with the NOVAP experiment, except that they are confined to lower levels (around $2 \mathrm{~km}$ ) owing to weaker vertical motion (strong vertical velocities extend to altitudes exceeding $5 \mathrm{~km}$ in the IDEAL experiment, whereas they only extend to $2 \mathrm{~km}$ in the FakeDry experiment - not shown). The latent heating can strengthen vertical movement and extend the LSB circulations to higher altitudes. The latent heating feedback can also lead to stronger and earlier convection initiation and precipi- 

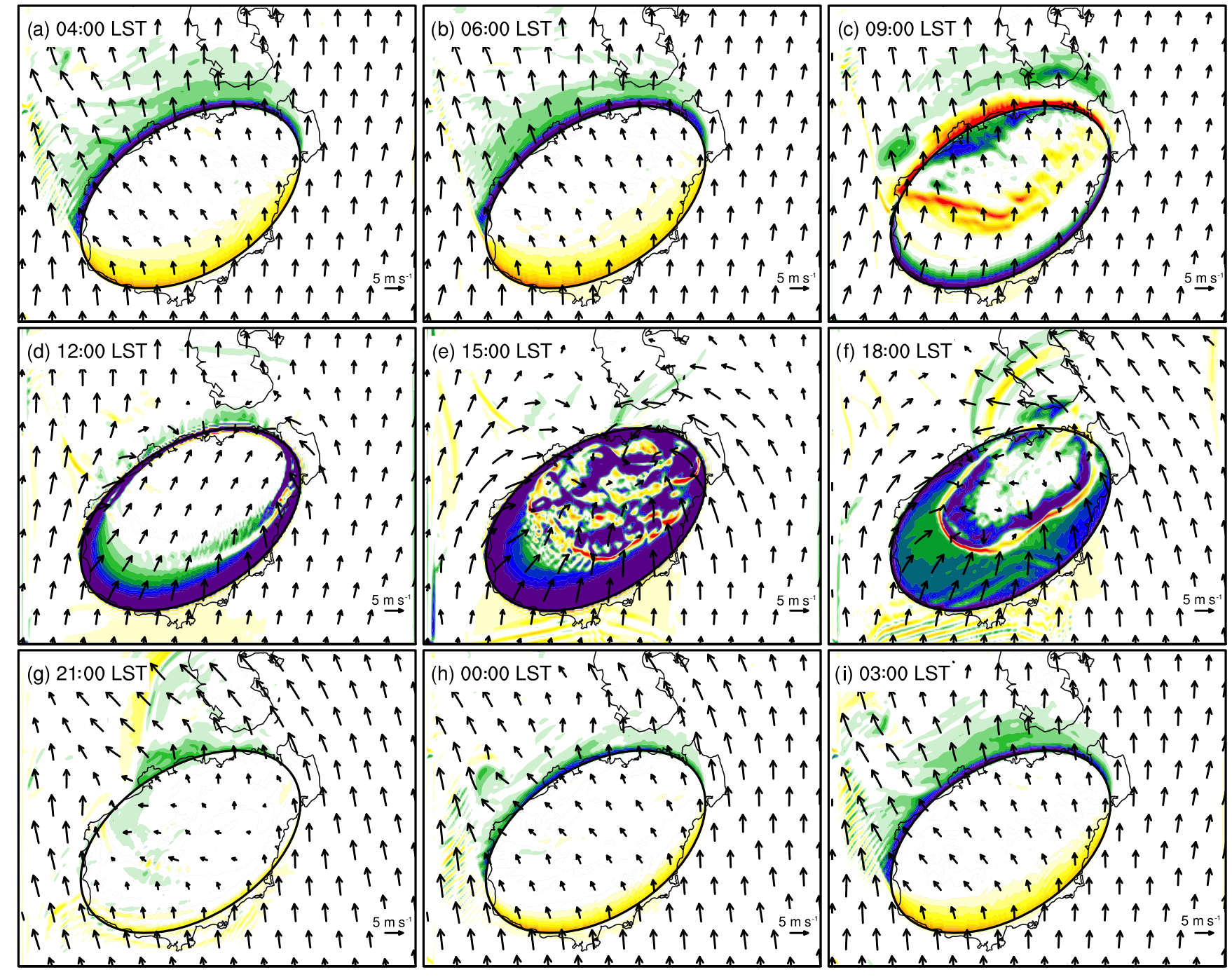

\begin{tabular}{lllllll|l}
-0.5 & -0.25 & 0 & 0.25 & 0.5
\end{tabular}

Figure 15. Horizontal temperature advection (shaded) and horizontal wind (vector, $\mathrm{m} \mathrm{s}^{-1}$ ) on the first model level in the IDEAL experiment.

tation along the sea-breeze fronts. In turn, the cold pool further promotes the inland penetration of the sea-breeze front and dissipates the precipitation (Fig. 16), which is because the pressure gradient increases and drives the sea-breeze flow more inland when the cold pool moves toward the island and inland.

\section{Summary}

The diurnal cycle of precipitation over tropical areas is poorly captured by numerical models, owing to model uncertainties in depicting the physical mechanisms that underlie the diurnal precipitation cycle, which is considered to be closely linked with the land-sea breeze. This study explored the diurnal precipitation variation and its relationship with the land-sea breeze circulations on Hainan Island, a tropical island located off the southern coast of China, based on gauge observation and satellite-estimated precipitation, as well as convection-permitting numerical simulations. The diurnal cycle of precipitation in each month over the island was analyzed with 19 gauge observations during 1951-2012. Most precipitation falls during the warm season (from April to October) and exhibit a significant diurnal cycle, whereas much less precipitation falls in other months. Precipitation is at a maximum between 15:00 and 17:00 LST in the warm season at almost all stations except for four stations along the southern coastline of the island.

The satellite-derived CMORPH precipitation estimates from 2006 to 2015 were further used to validate the diurnal precipitation variation. The CMORPH data agree well 


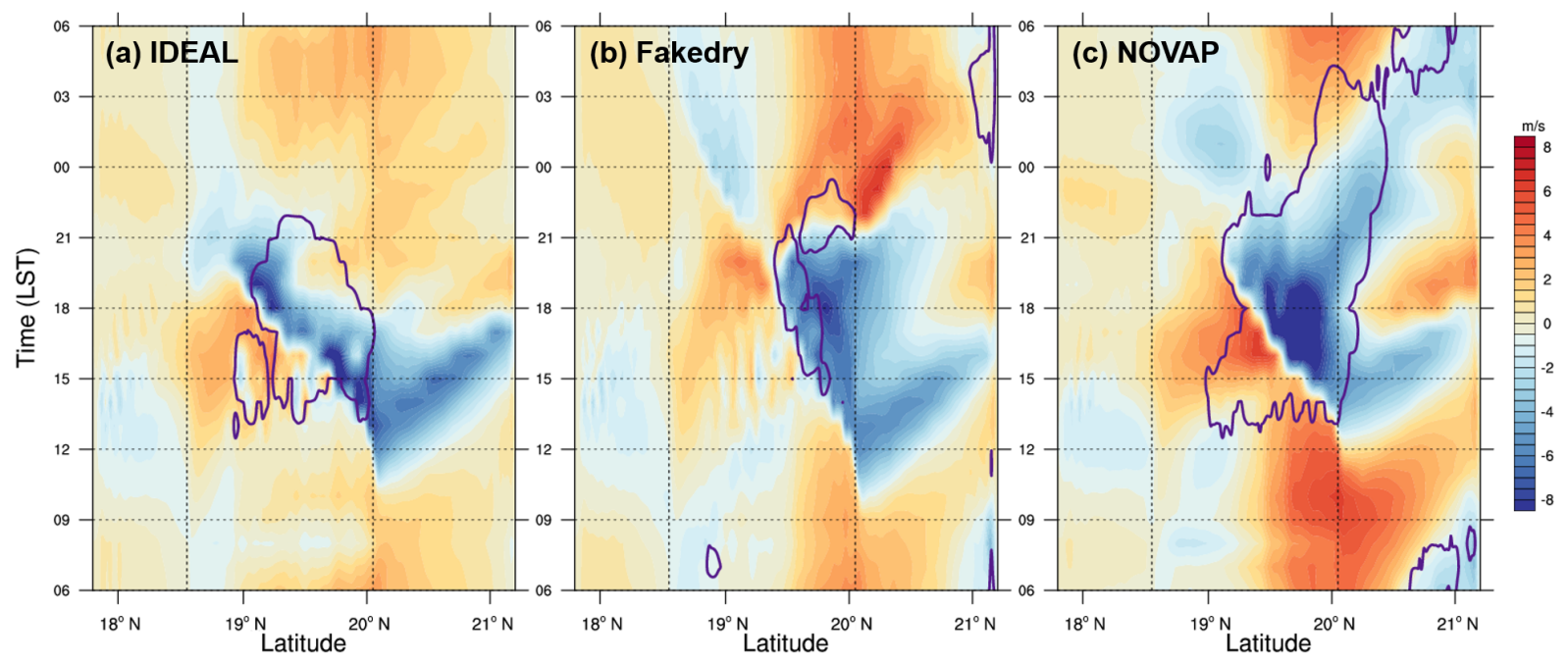

Figure 16. Hovmöller diagrams of perturbation meridional wind component on the second-lowest model level for horizontal wind (shading) in the (a) IDEAL, (b) Fakedry, and (c) NOVAP experiments, respectively. Precipitation exceeding $0.1 \mathrm{mmh}^{-1}$ is enclosed by the heavy purple contours. The two vertical dashed lines indicate the edges of the island.

with the gauge observation except for a smaller magnitude of precipitation and a $1 \mathrm{~h}$ delay in the timing of the daily precipitation maximum during the warm season. The analysis of CMORPH data shows that about $60 \%$ of the total annual precipitation over the island is attributable to diurnal variations, with the largest proportion in May and the smallest proportion in September and October. For May and June, precipitation begins around local noontime, intensifying quickly thereafter, and reaching a peak at $\sim 15$ :00 LST based on station observations. This diurnal rainfall cycle is, for the most part, consistent with the diurnally varying lowlevel wind convergence and divergence.

A series of numerical simulations (REAL, NoTER, IDEAL, FakeDry, and NOVAP) using a convectionpermitting configuration of the WRF model $(2 \mathrm{~km}$ horizontal grid spacing) were conducted to understand the underlying mechanisms of the diurnal precipitation variations. The initial and lateral boundary conditions were generated using a 10-year (2006-2015) average of ERA-Interim data for May and June. Results show that the orography of Hainan Island may have only a secondary influence on the diurnal precipitation cycle, which is different from past studies on other hilly islands. Similar diurnal cycles of precipitation and related land-sea breeze circulations were simulated between simulations with and without orography over the island. Even with an idealized elliptical and flat island covered by only grassland, located at the same place with similar area and orientation, the diurnal cycle characteristics can still be fairly well captured. Those results show that (1) WRF is capable of replicating the important aspects of the mean diurnal cycle in comparison to the rainfall observations, (2) removing the orography and coastal features made little difference to the diurnal cycle during the rainiest times of the year,
(3) the dominant process that produces the diurnal cycle was shown to be the land-sea breezes caused by the surface heating/cooling of the island relative to the surrounding ocean, and (4) evaporative cooling as part of convective systems also plays an important role in the diurnal cycle.

The simulated diurnal cycle of precipitation and related land-sea breeze circulations based on the idealized flatisland simulation were divided into four stages in terms of the evolutions of temperature, winds and precipitation. Stage 1 is from 06:00 to 12:00 LST, during which time the land breeze is replaced by a sea breeze as solar heating warms the interior of the island. Abundant moisture is transported to the low-to-middle troposphere over the island, resulting in convective initiation and precipitation along the sea-breeze front. Stage 2 is from 12:00 to 18:00 LST, during which time the sea breeze attains to its peak intensity, and precipitation is at a maximum. The sea breezes from opposite sides of the island eventually penetrate all the way to the island's center and collide, which results in the maximum precipitation being located there. Stage 3 is from 18:00 to 00:00 LST, during which time a land breeze is established as a result of the cooling over the island. The cooling is due primarily to the sudden loss of solar heating. Subsidence from the land breeze prevents further precipitation by early evening. The last stage covers the peak of the land breeze, which is observed around sunrise.

The FakeDry and NOVAP experiments show that the latent cooling and cold pool have a small impact on the landsea breeze circulations but can apparently enhance precipitation. Strong convection can enhance the sea breeze, and the augmentation of the sea breeze by the evaporatively driven cold pool helps to accelerate the inland propagation of the sea breeze and weakens the convection. 
Finally, it is worth mentioning that the $1 \mathrm{~h}$ delay in the timing of the maximum precipitation in the simulation is probably caused by the $2 \mathrm{~km}$ horizontal resolution, which may not be high enough to resolve explicit underlying physical processes. It is likely for the same reason that the weak nocturnal precipitation is not captured by the simulations. Much higher horizontal and vertical resolution might be needed in future work to resolve more detailed processes related to the diurnal cycles. On the other hand, there are many other factors like biases in ERA-Interim reanalysis data used for the initial and boundary conditions to drive the numerical simulations and biases in physical processes (microphysics, surface processes, radiative process, etc), which will be studied in follow-up work. Moreover, the rainfall for different seasons shows quite different patterns, owing to various underlying dynamic and thermodynamic physics. In addition to May and June, which were mainly examined in the current work, the diurnal rainfall variation in other months needs to be explored in further studies.

Data availability. All the model output data and the station observation data have been stored and can be accessed through the Texas Advanced Computing Center (TACC) data archive. The CMORPH data can be freely accessed at the link ftp://ftp.cpc.ncep. noaa.gov/precip/global_CMORPH/30min_8km. The ERA-Interim data can also be freely accessed at the link https://rda.ucar.edu/ datasets/ds627.0/?hash=!access. Both the CMORPH and ERAInterim data also can be accessed through the TACC data archive. Please contact the corresponding author for details via email (zymeng@pku.edu.cn).

Competing interests. The authors declare that they have no conflict of interest.

Acknowledgements. Lei Zhu is supported by the Natural Science Foundation of China grant 41461164006, and the Chinese Scholarship Council (CSC). Zhiyong Meng is supported by the Natural Science Foundation of China grants 41461164006, 41425018 and 41375048. Fuqing Zhang is supported by the Office of Naval Research grant N000140910526 and the National Science Foundation grant AGS-1305798. Paul Markowski is supported by the National Science Foundation grant AGS-1536460 and the National Oceanic and Atmospheric Administration awards NA15NWS4680012 and NA14NWS4680015. The simulations were performed on the Stampede supercomputer of the Texas Advanced Computing Center (TACC). All data are freely available from sources indicated in the text or from the corresponding author upon request (email: zymeng@pku.edu.cn).

Edited by: Geraint Vaughan

Reviewed by: two anonymous referees

\section{References}

Bao, X. and Zhang, F.: Impacts of the mountain-plains solenoid and cold pool dynamics on the diurnal variation of warm-season precipitation over northern China, Atmos. Chem. Phys., 13, 69656982, https://doi.org/10.5194/acp-13-6965-2013, 2013.

Bao, X., Zhang, F., and Sun, J.: Diurnal variations of warmseason precipitation east of the Tibetan Plateau over China, Mon. Weather Rev., 139, 2790-2810, 2011.

Barthlott, C. and Kirshbaum, D. J.: Sensitivity of deep convection to terrain forcing over Mediterranean islands, Q. J. Roy. Meteor. Soc., 139, 1762-1779, 2013.

Chen, X., Zhang, F., and Zhao, K.: Diurnal variations of the landsea breeze and its related precipitation over South China, J. Atmos. Sci., 73, 4793-4815, 2016.

Chen, X., Zhang, F., and Zhao, K.: Influence of monsoonal wind speed and moisture content on intensity and diurnal variations of the Mei-yu season coastal rainfall over South China, J. Atmos. Sci., in press, https://doi.org/10.1175/JAS-D-17-0081.1, 2017.

Crosman, E. T. and Horel, J. D.: Sea and lake breezes: a review of numerical studies, Bound.-Lay. Meteorol., 137, 1-29, 2010.

Dai, A.: Global precipitation and thunderstorm frequencies, Part I: Seasonal and interannual variations, J. Clim., 14, 1092-1111, 2001.

Dee, D. P., Uppala, S. M., Simmons, A. J., Berrisford, P., Poli, P., Kobayashi, S., Andrae, U., Balmaseda, M. A., Balsamo, G., Bauer, P., and Bechtold, P.: The ERA-Interim reanalysis: configuration and performance of the data assimilation system, Q. J. Roy. Meteor. Soc., 137, 553-597, 2011.

Dudhia, J.: Numerical study of convection observed during the winter monsoon experiment using a mesoscale two-dimensional model, J. Atmos. Sci., 46, 3077-3107, 1989.

Han, J. Y. and Baik, J. J.: A theoretical and numerical study of urban heat island-induced circulation and convection, J. Atmos. Sci., 65, 1859-1877, 2008.

Hassim, M. E. E., Lane, T. P., and Grabowski, W. W.: The diurnal cycle of rainfall over New Guinea in convectionpermitting WRF simulations, Atmos. Chem. Phys., 16, 161-175, https://doi.org/10.5194/acp-16-161-2016, 2016.

He, H. and Zhang, F.: Diurnal variations of warm-season precipitation over northern China, Mon. Weather Rev., 138, 1017-1025, 2010.

Hong, S. Y., Dudhia, J., and Chen, S. H.: A revised approach to ice microphysical processes for the bulk parameterization of clouds and precipitation, Mon. Weather Rev., 132, 103-120, 2004.

Hong, S. Y., Noh, Y., and Dudhia, J.: A new vertical diffusion package with an explicit treatment of entrainment processes, Mon. Weather Rev., 134, 2318-2341, 2006.

Huffman, G. J., Bolvin, D. T., Nelkin, E. J., Wolff, D. B., Adler, R. F., Gu, G., Hong, Y., Bowman, K. P., and Stocker, E. F.: The TRMM multisatellite precipitation analysis (TMPA): quasiglobal, multiyear, combined-sensor precipitation estimates at fine scales, J. Hydrometeorol., 8, 38-55, 2007.

Iacono, M. J., Delamere, J. S., Mlawer, E. J., Shephard, M. W., Clough, S. A., and Collins, W. D.: Radiative forcing by longlived greenhouse gases: Calculations with the AER radiative transfer models, J. Geophys. Res.-Atmos., 113, D13103, https://doi.org/10.1029/2008JD009944, 2008.

Joyce, R. J., Janowiak, J. E., Arkin, P. A., and Xie, P.: CMORPH: a method that produces global precipitation estimates from pas- 
sive microwave and infrared data at high spatial and temporal resolution, J. Hydrometeorol., 5, 487-503, 2004.

Keenan, T. D., Holland, G. J., Manton, M. J., and Simpson, J.: TRMM ground truth in a monsoon environment: Darwin, Australia, Aust. Meteorol. Mag., 36, 81-90, 1988.

Kishtawal, C. M. and Krishnamurti, T. N.: Diurnal variation of summer rainfall over Taiwan and its detection using TRMM observations, J. Appl. Meteorol., 40, 331-344, 2001.

Liang, Z. and Wang, D.: Sea breeze and precipitation over Hainan Island, Q. J. Roy. Meteor. Soc., 143, 137-151, https://doi.org/10.1002/qj.2952, 2017.

Mapes, B. E., Warner, T. T., and Xu, M.: Diurnal patterns of rainfall in northwestern South America. Part III: Diurnal gravity waves and nocturnal convection offshore, Mon. Weather Rev., 131, 830-844, 2003.

Neale, R. and Slingo, J.: The maritime continent and its role in the global climate: a GCM study, J. Clim., 16, 834-848, 2003.

Nguyen, H., Protat, A., Kumar, V., Rauniyar, S., Whimpey, M., and Rikus, L.: A regional forecast model evaluation of statistical rainfall properties using the CPOL radar observations in different precipitation regimes over Darwin, Australia, Q. J. Roy. Meteor. Soc., 141, 2337-2349, 2015.

Ogino, S. Y., Yamanaka, M. D., Mori, S., and Matsumoto, J.: How Much is the Precipitation Amount over the Tropical Coastal Region?, J. Clim., 29, 1231-1236, 2016.

Qian, J. H.: Why precipitation is mostly concentrated over islands in the Maritime Continent, J. Atmos. Sci., 65, 1428-1441, 2008.

Skamarock, W. C., Klemp, J. B., Dudhia, J., Gill, D. O., Barker, D. M., Duda, M. G., Huang, X. Y., Wang, W., and Powers, J. G.: A Description of the Advanced Research WRF Version 3, NCAR Tech. Note NCAR/TN-475+STR, 113 pp., https://doi.org/10.5065/D68S4MVH, 2008.
Sobel, A. H., Burleyson, C. D., and Yuter, S. E.: Rain on small tropical islands, J. Geophys. Res.-Atmos., 116, D08102, https://doi.org/10.1029/2010JD014695, 2011.

Sun, J. and Zhang, F.: Impacts of mountain-plains solenoid on diurnal variations of rainfalls along the mei-yu front over the east China plains, Mon. Weather Rev., 140, 379-397, 2012.

Trier, S. B., Davis, C. A., and Ahijevych, D. A.: Environmental controls on the simulated diurnal cycle of warm-season precipitation in the continental United States, J. Atmos. Sci., 67, 1066-1090, 2010.

Tu, X., Zhou, M. Y., Z., and Sheng, S. H.: The mesoscale numerical simulation of the flow field of the Hainan Island and the Leizhou Peninsula, Acta Oceanol. Sin., 12, 219-235, 1993.

Wapler, K. and Lane, T. P.: A case of offshore convective initiation by interacting land breezes near Darwin, Australia, Meteorol. Atmos. Phys., 115, 123-137, 2012.

Yang, G. Y. and Slingo, J.: The diurnal cycle in the tropics, Mon. Weather Rev., 129, 784-801, 2001.

Zhai, W., Li, G., Sun, B., and Dang, R.: Varying season's mesoscale wind field circulation in Hainan island, J. Trop. Meteorol., 4, 7987, 1998.

Zhang, Y., Zhang, F., and Sun, J.: Comparison of the diurnal variations of warm-season precipitation for East Asia vs. North America downstream of the Tibetan Plateau vs. the Rocky Mountains, Atmos. Chem. Phys., 14, 10741-10759, https://doi.org/10.5194/acp-14-10741-2014, 2014. 